\title{
Translating neural stem cells to neurons in the mammalian brain
}

\author{
Siraj K. Zahr ${ }^{1,2} \cdot$ David R. Kaplan ${ }^{1,2,3} \cdot$ Freda D. Miller ${ }^{1,2,3,4}$
}

Received: 28 April 2019 / Revised: 5 July 2019 / Accepted: 8 August 2019 / Published online: 24 September 2019

(c) The Author(s), under exclusive licence to ADMC Associazione Differenziamento e Morte Cellulare 2019

\begin{abstract}
The mammalian neocortex underlies our perception of sensory information, performance of motor activities, and higherorder cognition. During mammalian embryogenesis, radial glial precursor cells sequentially give rise to diverse populations of excitatory cortical neurons, followed by astrocytes and oligodendrocytes. A subpopulation of these embryonic neural precursors persists into adulthood as neural stem cells, which give rise to inhibitory interneurons and glia. Although the intrinsic mechanisms instructing the genesis of these distinct progeny have been well-studied, most work to date has focused on transcriptional, epigenetic, and cell-cycle control. Recent studies, however, have shown that posttranscriptional mechanisms also regulate the cell fate choices of transcriptionally primed neural precursors during cortical development. These mechanisms are mediated primarily by RNA-binding proteins and microRNAs that coordinately regulate mRNA translation, stability, splicing, and localization. Together, these findings point to an extensive network of posttranscriptional control and provide insight into both normal cortical development and disease. They also add another layer of complexity to brain development and raise important biological questions for future investigation.
\end{abstract}

\section{Facts}

- Numerous posttranscriptional regulators including RBPs and miRNAs are expressed in a temporally dynamic and cell-type specific manner during embryonic corticogenesis.

- Posttranscriptional mechanisms control cell fate decisions of embryonic and adult neural precursor cells.

- Environmentally-driven signaling cascades regulate the expression and activity of posttranscriptional machinery.

- Neural precursor cells are transcriptionally primed and posttranscriptional mechanisms selectively repress

Edited by G. Melino

David R. Kaplan

dkaplan@sickkids.ca

1 Program in Neurosciences and Mental Health, Hospital for Sick Children, Toronto, ON M5G 1L7, Canada

2 Institute of Medical Science, University of Toronto, Toronto, ON M5G 1A8, Canada

3 Department of Molecular Genetics, University of Toronto, Toronto, ON M5G 1A8, Canada

4 Department of Physiology, University of Toronto, Toronto, ON M5G 1A8, Canada
mRNA translation to regulate self-renewal versus differentiation.

\section{Open questions}

- Is transcriptional priming and posttranscriptional control a general cellular strategy employed in developing and adult mammalian stem cell compartments?

- How do individual RBPs and miRNAs fit within the larger network of posttranscriptional control?

- What are the environmental cues that regulate the expression and activity of posttranscriptional machinery?

- How does the posttranscriptional machinery interface with transcriptional and epigenetic mechanisms?

- How do RBPs and miRNAs contribute to neurodevelopmental and neurological disorders?

\section{Introduction}

The mammalian neocortex is the most evolutionarily recent structure of the central nervous system and is responsible for processing sensory information, controlling motor output, and mediating higher-order cognitive functions [1]. Excitatory neocortical neurons are generated from neural 
precursor cells (NPCs) between embryonic (E) days 10.5 and E17.5 in mice and gestational week 7-27 in humans, followed by astrocytes and oligodendrocytes [1]. Production of the correct number and subtypes of neurons during this critical developmental window is crucial for the formation of functional neural circuitry, and defects in this process contribute to neurodevelopmental and neurological disorders including microcephaly, autism spectrum disorder, epilepsy, and schizophrenia [2]. In this review, we provide an overview of embryonic and adult ventricularsubventricular zone (V-SVZ) neurogenesis and the emerging role of posttranscriptional control. We also discuss the concept of transcriptional priming in the context of posttranscriptional mechanisms. Finally, we integrate these findings into a model of posttranscriptional control of neurogenesis.

\section{Overview of embryonic cortical neurogenesis}

The neocortex develops from the dorsal telencephalon, which begins as a pseudostratified neuroepithelial cell layer consisting of mitotically-active neuroepithelial stem cells (NESCs). This cortical layer, known as the ventricular zone (VZ), forms at E8-9 in mice [3, 4]. NESCs divide symmetrically to expand the precursor pool before transitioning into radial glial precursor cells (RGPs, also known as apical precursors) between E10-12, prior to the onset of cortical neurogenesis (Fig. 1a) [3, 5]. Unlike NESCs, which are limited to symmetric divisions, RGPs primarily divide asymmetrically to give rise to cortical excitatory neurons directly or indirectly by generating intermediate/basal progenitors (IP/BP) with limited cell division capacity that each produce two neurons (Fig. 1a) [3]. IPs populate the space immediately basal to the VZ known as the subventricular zone (SVZ), and provide a means of amplifying the neuronal output per neurogenic division [6]. The SVZ also contains another self-renewing precursor cell called outer/ basal radial glia, which are abundant in gyrencephalic animals such as ferrets and primates [7].

The projection neurons that comprise the mature cortex are arranged into six layers and differ with regard to their morphology, axonal connectivity, electrophysiology, and gene expression [4]. These neurons are generated in an inside-out fashion to populate the six layers of the cortex, with earlier-born neurons populating the deepest of the six cortical layers, while later-born neurons populate progressively more superficial layers (Fig. 1a) [4]. While transcriptional profiling of purified populations of projection neurons in various cortical layers have identified important markers [8], these population-based studies do not fully account for the cellular and molecular heterogeneity that is beginning to be elucidated with single-cell RNA sequencing approaches [9].

\section{Models of neurogenesis}

In vivo lineage tracing studies indicate that early RGPs are multipotent and sequentially give rise to deep and superficial layer neurons followed by glia [1, 3, 4, 10, 11]. How are these different layer neurons generated from a pool of multipotent RGPs during neurogenesis? Until recently, the prevailing model based on classical transplantation experiments in ferrets was that an initial pool of multipotent progenitors undergoes progressive fate restriction throughout neurogenesis as they sequentially generate deep and superficial layer neurons [12]. Recent work, however has challenged this idea [13]. In this study, a FlashTag approach was used to pulse-label and isolate E15 RGPs that normally only generate later-born superficial neurons. When these tagged RGPs were transplanted into younger E12 embryonic cortices, they reverted to an E12-like RGP state and generated deep-layer neurons, just like the endogenous RGPs [13]. These findings suggest that RGPs do not become fate restricted as they transition from making deep-layer to superficial layer neurons, but that it is the environment that dictates genesis of one neuron type versus another.

\section{Intrinsic regulation of embryonic cortical development}

The precise balance between RGP self-renewal and differentiation in the developing neocortex involves the interaction of intrinsic cellular programs with a multitude of environmental cues. Rather than simply generating a homogeneous population of neurons, RGPs must sequentially give rise to diverse neuronal subtypes that populate the different layers of the cortex. How does neuronal subtype specification occur? Gain- and loss-of-function studies have shown that the transcription factors Sox5, Satb2, Fezf2, Tbr1, and Ctip2 comprise a cross-repressive transcriptional circuit that regulates projection neuron specification (Fig. 1b) [1, 4, 10]. Many additional subtype-specific genes have since been identified including the transcription factors Brn $1 / 2$ and Rorb that play critical roles in specification [8, 14, 15]. While this transcriptional circuit model has experimental support, the precise molecular controls underlying neuronal subtype specification are likely much more elaborate.

The ability of transcription factors to execute their function requires accessible chromatin sites on DNA, and neural precursors undergo extensive epigenetic changes during corticogenesis, particularly during the neurogenic-togliogenic transition [16, 17]. In addition to epigenetic control, regulation of cell-cycle length is another intrinsic regulator of NPC activity. We refer the reader to excellent 

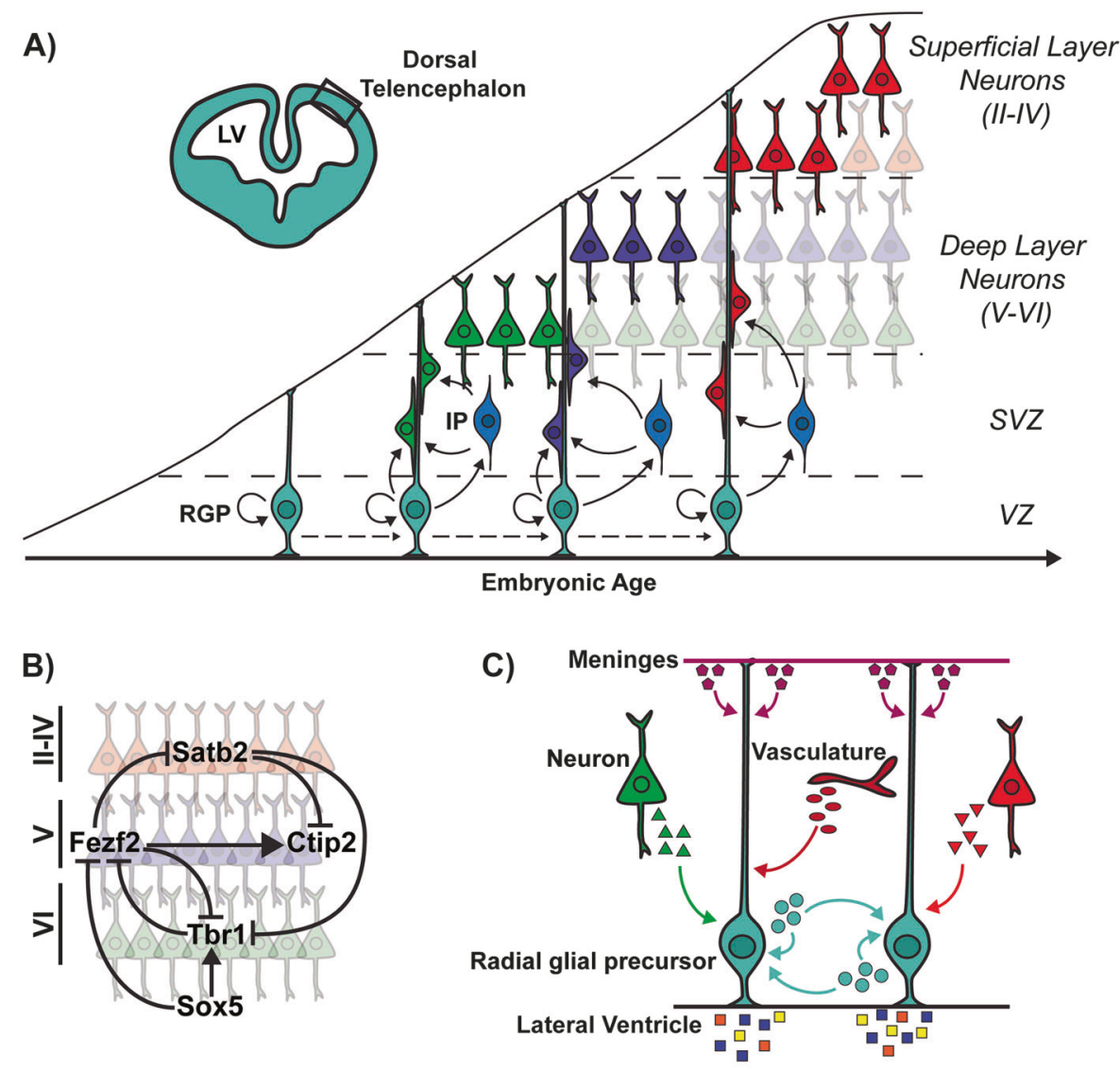

$$
\begin{aligned}
& \text { - Vasculature cues } \\
& \nabla \Delta \text { Neuronal cues } \\
& \text { - Cerebrospinal fluid cues } \\
& \text { - Radial glial precursor cues } \\
& \text { Meningeal cues }
\end{aligned}
$$

Fig. 1 Embryonic cortical neurogenesis occurs in an inside-out fashion. a In the developing dorsal telencephalon, radial glial precursors (RGPs) residing in the ventricular zone (VZ) adjacent to the lateral ventricles $(\mathrm{LV})$ can give rise to a postmitotic neuron directly or indirectly via an intermediate progenitor (IP) cell. IPs populate the space basal to the VZ known as the subventricular zone (SVZ). Cortical neurons are generated in an inside-out fashion to populate the six layers of the cortex. Earlier-born neurons (shown in green and purple) populate the deepest of the six cortical layers $(\mathrm{V}-\mathrm{VI})$, while later born neurons (shown in red) populate progressively more superficial layers (II-IV). These layers contain distinct neuronal subtypes that differ based on morphology, electrophysiological activity, axonal connectivity, and gene expression. b Illustration of a cross-repressive

reviews on transcriptional, epigenetic, and cell-cycle control during neurogenesis $[10,11,16,18,19]$.

\section{Extrinsic cues regulating embryonic cortical development}

The elongated radial morphology of RGPs provides them with access to extrinsic cues originating from the meninges, vasculature, newborn neurons, and transcriptional circuit that regulates deep versus superficial layer neuron specification $[1,4]$. Tbr1 specifies deep layer VI corticothalamic neurons (shown in green) in part by repressing Fezf2, while Fezf2 acts upstream of Ctip2 to specify deep layer $\mathrm{V}$ subcerebral neurons (shown in purple) $[1,4]$. Sox 5 regulates the timing of deep layer neurogenesis by repressing Fezf2 until the production of layer VI corticothalamic neurons is complete. Satb2 specifies upper layer neurons (shown in red) in part by repressing deep-layer neuronal specifiers Ctip2 and Tbr1 [1, 4]. c RGPs integrate autocrine and paracrine factors originating from several sources including the meninges, vasculature, newborn neurons, and cerebrospinal fluid (CSF), many of which regulate RGP cell fate decisions

cerebrospinal fluid, many of which regulate RGP cell fate decisions (Fig. 1c) [18, 20]. In this regard, combined transcriptome and cell-surface proteomic analysis of NPCs and newborn neurons have revealed a rich growth factor environment in the developing cortex including many previously uncharacterized autocrine and paracrine interactions (Fig. 1c) [20]. In addition to generically controlling NPC proliferation and differentiation, extrinsic cues regulate the specification of particular neuronal 
subtypes [21]. We refer the reader to excellent reviews on this topic [18, 21].

\section{Going beyond transcriptional and epigenetic mechanisms: posttranscriptional control of gene expression}

Appropriate gene expression requires that proteins are produced at the correct time, amount, and subcellular location. How much do posttranscriptional regulatory mechanisms, for example those controlling translation, regulate this process? Conventionally, mRNA concentration in mammalian cells was assumed to be highly concordant with protein concentration, and mRNA levels were thus commonly used as a proxy for protein levels. However, systems-wide studies have highlighted why this is not always a correct assumption. In this regard, numerous studies have found a moderate to low correlation between protein and mRNA levels, with translation rates contributing to a large percentage of the variance in protein levels $[22,23]$. Other studies have challenged this conclusion, showing high correlations between mRNA and protein levels $\left(R^{2} \sim 0.6-0.9\right)$, arguing that transcriptional control makes the largest contribution to protein levels [22, 23].

Although transcription is considered the main predictor of protein levels under steady state conditions, posttranscriptional control has been shown to play a dominant role during short-term state transitions such as differentiation $[22,24,25]$. The ability to change mRNA "translation on demand" allows proteins to be rapidly available in response to extrinsic stimuli and cellular changes [22]. Transcription factors are particularly subject to this form of regulation during rapid state transitions [26]. Furthermore, transcription is often spontaneous and stochastic, and the resulting transcriptional noise can be partially buffered by translational mechanisms to avoid aberrant cell fate decisions [22].

Posttranscriptional control is largely mediated by RNA-binding proteins (RBPs) and microRNAs (miRNAs), which assemble on mRNA sequences, often located in $3^{\prime}$ untranslated regions (3'UTRs) [27]. In addition to $\sim 1600$ transcription factors, there are over 1500 RBPs and 2600 annotated mature miRNAs encoded by the human genome [28-30]. RBPs are highly ubiquitous trans-acting regulators that influence various steps of RNA metabolism including mRNA stability, nuclear export, splicing, localization, and translation (Fig. 2a) [31]. RBPs and miRNAs regulate groups of functionallyrelated mRNAs along a coordinated pathway of RNA processing, allowing cells to respond with unprecedented efficiency to extrinsic cues, in what has been termed the 'RNA-operon' theory [31].

\section{RBPs regulate multiple aspects of embryonic cortical development}

Although most work to date has focused on epigenetic and transcriptional mechanisms, the role of posttranscriptional control in cortical development has only recently been appreciated. Microarray analysis at different timepoints throughout corticogenesis revealed that numerous posttranscriptional regulatory factors involved in mRNA splicing, localization, stability, and translation are dynamically expressed across the neurogenic period, particularly those involved in translational control [32]. A large number of RBPs were dynamically expressed, and single-molecule fluorescence in situ hybridization analyses found that their expression patterns were not only temporally dynamic but cell-type specific in several cases [32,33]. The combination of ribosomal proteins associated with translating polysomes is also dynamic in both time and space throughout cortical development [34]. Intriguingly, while levels of many mRNAs encoding transcriptional and translational regulators are unaltered over cortical development, they are differentially associated with translating polysomes in a temporally-specific manner, suggesting that the posttranscriptional regulators may themselves be subject to posttranscriptional regulation [34]. Like RBPs, numerous miRNAs are also expressed in a temporally dynamic and cell-type specific manner during mammalian corticogenesis [35-37]. Several miRNAs and RBPs play key roles in multiple aspects of cortical development including NPC maintenance, differentiation, specification, neuronal migration, and survival. We will not focus on miRNA regulation in this review (see Table 2 and reviews [27, 38]). Instead, we will highlight several RBPs with a focus on those that regulate cell fate decisions in the developing cortex (Table 1). RBPs and miRNAs in the developing cortex, their main targets, and their functional roles are summarized in Tables 1 and 2, respectively.

\section{mRNA splicing}

Alternative splicing provides one way to amplify the protein diversity of the transcriptome by editing pre-mRNA sequences. In addition to modifying pre-mRNAs to generate unique protein-coding transcripts, alternative splicing modifies the $5^{\prime}$ and $3^{\prime}$ UTRs of mRNAs to impact downstream processing including mRNA translation, stability, and localization by exposing or concealing binding sites for RBPs and miRNAs (Fig. 2a) [39]. In the developing cortex, splicing is regulated in part by RBPs and plays a role in NPC maintenance, differentiation, survival, and neuronal migration (Table 1).

Several studies have shown dynamic alternative splicing changes in the developing forebrain across different brain regions, cell types, neuronal layers, and developmental stages 
Fig. 2 NPC activity is dynamically regulated by posttranscriptional mechanisms. a Radial glial precursors (RGPs, light blue) are dynamically regulated by posttranscriptional mechanisms. The boxed regions of the RGP cell body and basal process are shown at higher magnification at the right. RBPs (shown by colored hexagons, triangles, and ovals) and miRNAs (red/brown lines) are highly ubiquitous and influence various steps of RNA metabolism including mRNA splicing, nuclear export, stability, localization, and translation. In the basal process, mRNAs are actively transported by RBPs (such as FMRP) along microtubules (purple). A figure legend is shown in the lower right panel. b mRNA cell fate determinants are asymmetrically segregated and actively transported in RGPs to ensure appropriate cell fate decisions. In RGPs undergoing mitosis, a Staufen2-Pum2-Ddx1 complex asymmetrically segregates cell fate determinants such as Proxl mRNA into the daughter cell destined to become an intermediate progenitor (IP). mRNA cell fate determinants are actively transported to basal endfeet by FMRP, where they are locally translated. In RGP basal endfeet, self-renewal factors such as CyclinD2 mRNA are locally translated, ensuring that the daughter cell inheriting the basal process maintains its self-renewing capacity. A figure legend is shown in the lower right panel
A)
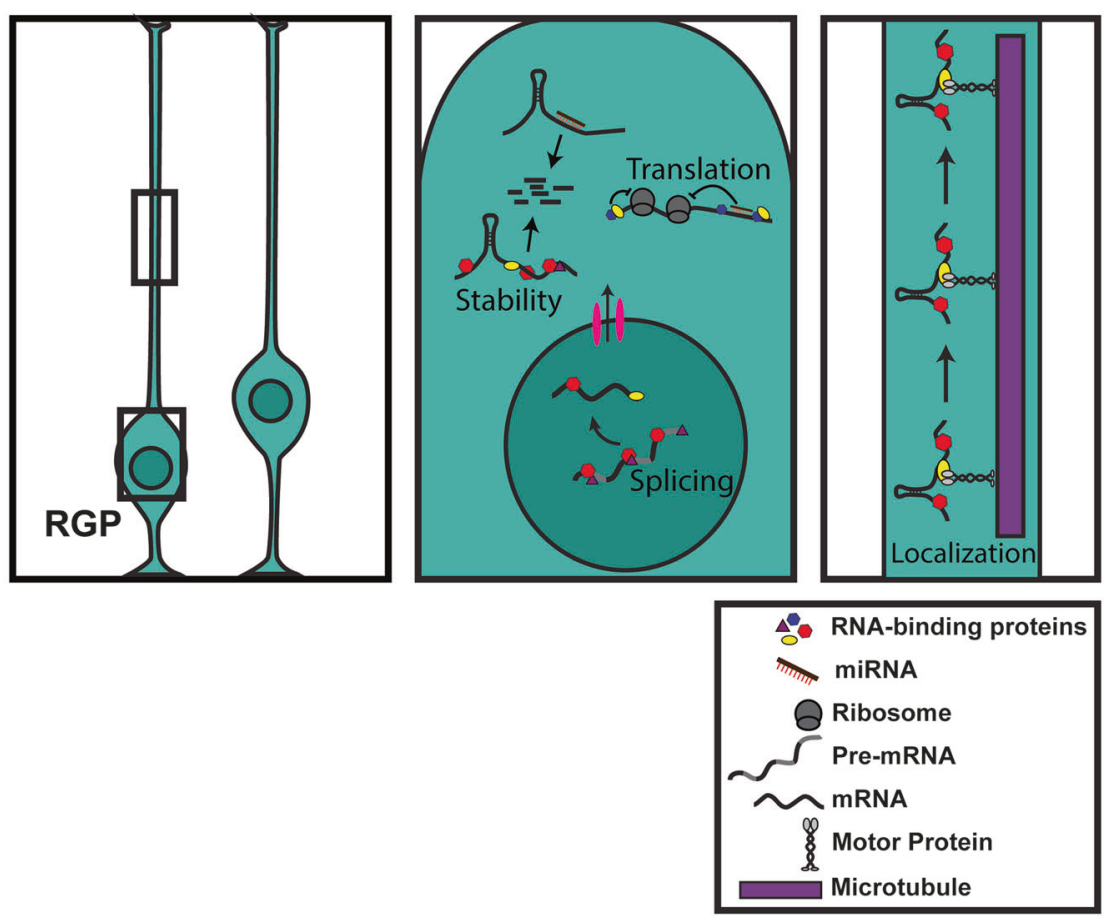

B)

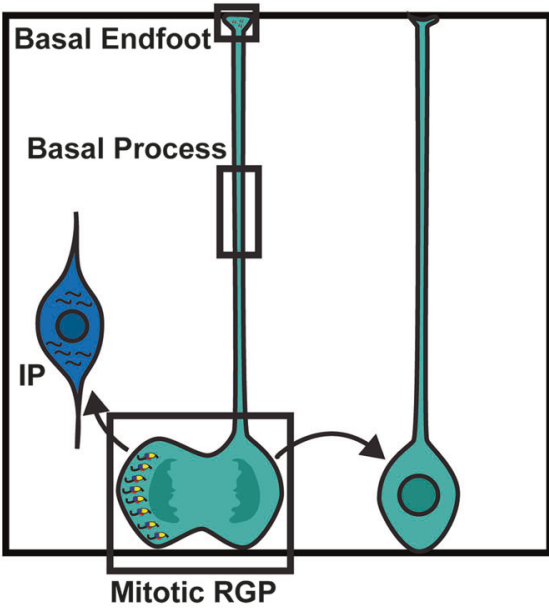

Assymetric Segregation
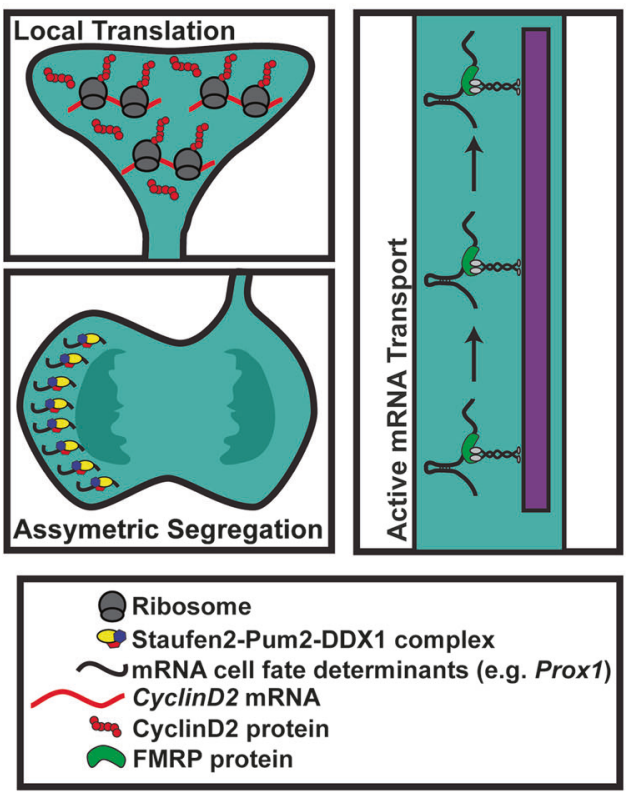

[8, 14, 40-45]. For example, cortical NPCs and neurons transcriptionally profiled using RNA-sequencing showed extensive alternative exon usage during neuronal differentiation, preferentially of genes encoding cytoskeletal proteins [44]. These splicing changes were partially mediated by the RBPs Ptbp 1 and Rbfox $1 / 2 / 3$ that antagonistically regulate the inclusion of neuronal exons to promote NPC maintenance and differentiation, respectively. Ptbp1 is expressed in RGPs and downregulated in neurons, and conditional knockdown of Ptbpl in RGPs caused loss of adherens junctions, premature neurogenesis, and lethal hydrocephalus postnatally
[44, 46, 47]. Ptbp1 maintained RGPs in part by suppressing the inclusion of neuronal exons such as poison exons in Filamin A and Filamin B (exons containing stop codons that result in mRNA decay). Ptbpl itself is a transcriptional target of Sox2, a master transcriptional regulator of NPC identity, suggesting that Sox2 acts in part via Ptbp1 regulation [44]. Ptbpl is translationally repressed by miR-124, resulting in the inclusion of neuron-specific exons and neuronal differentiation [48]. Together, these findings illustrate how posttranscriptional regulators are themselves regulated by both transcriptional and posttranscriptional mechanisms [27]. 


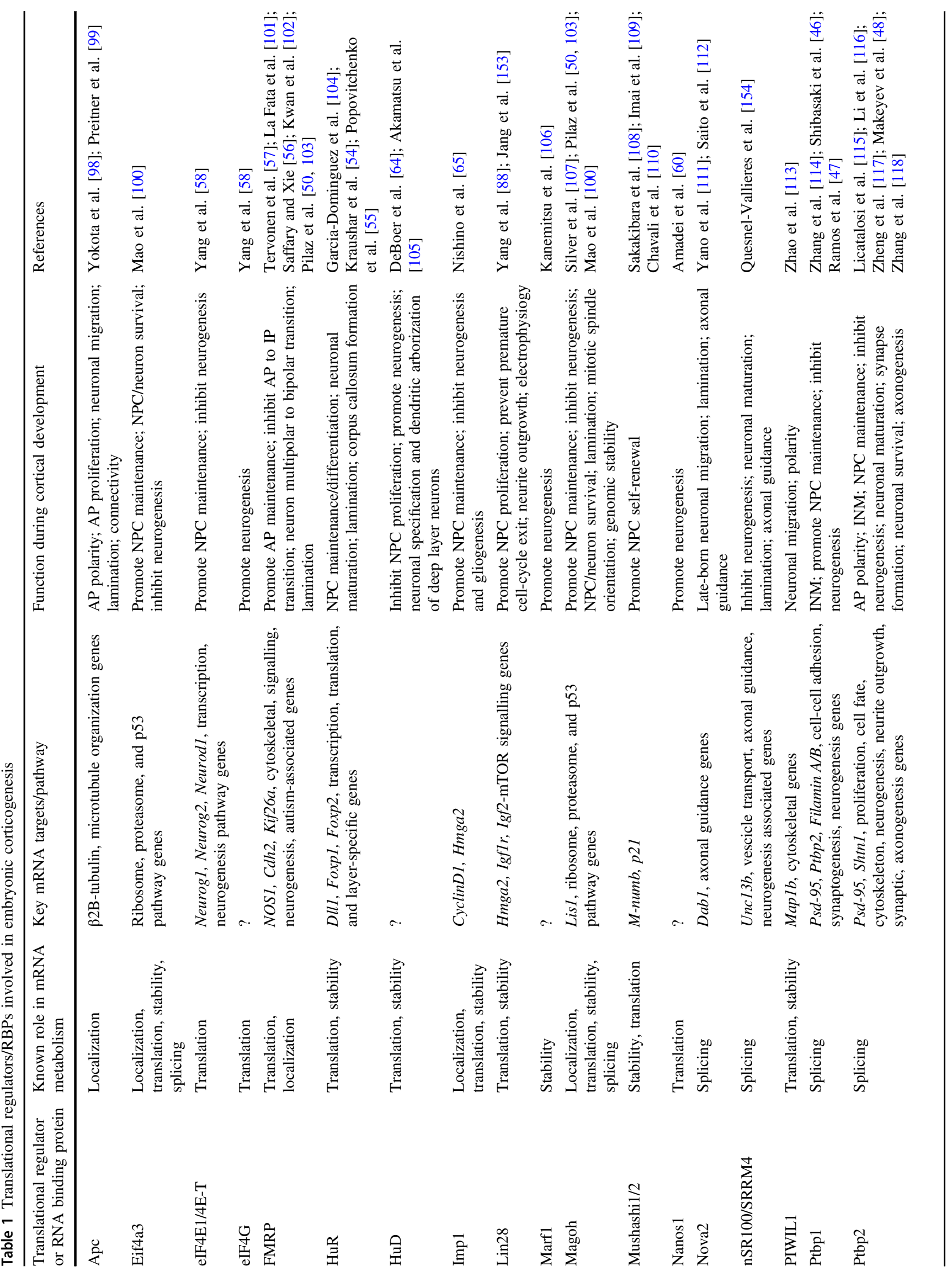




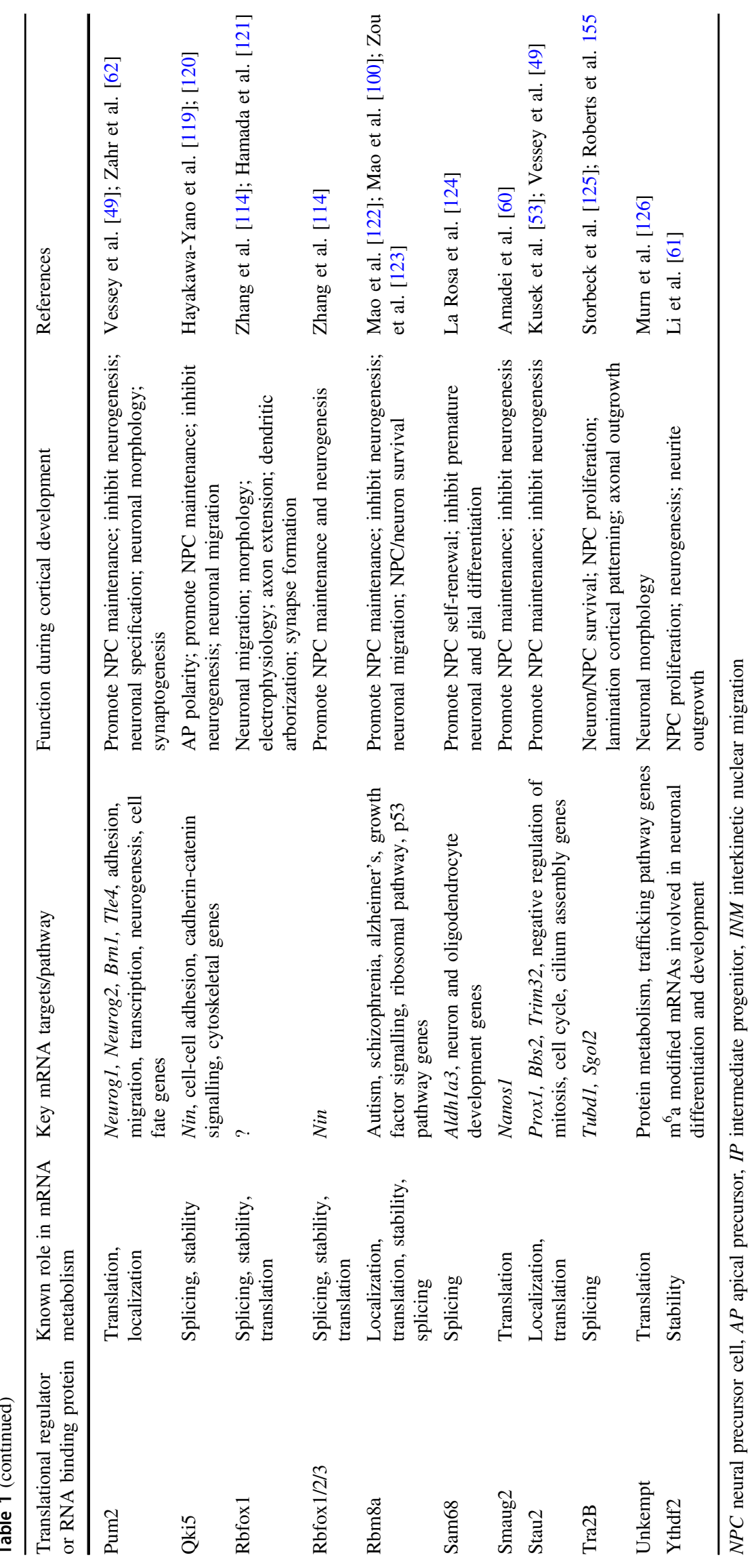




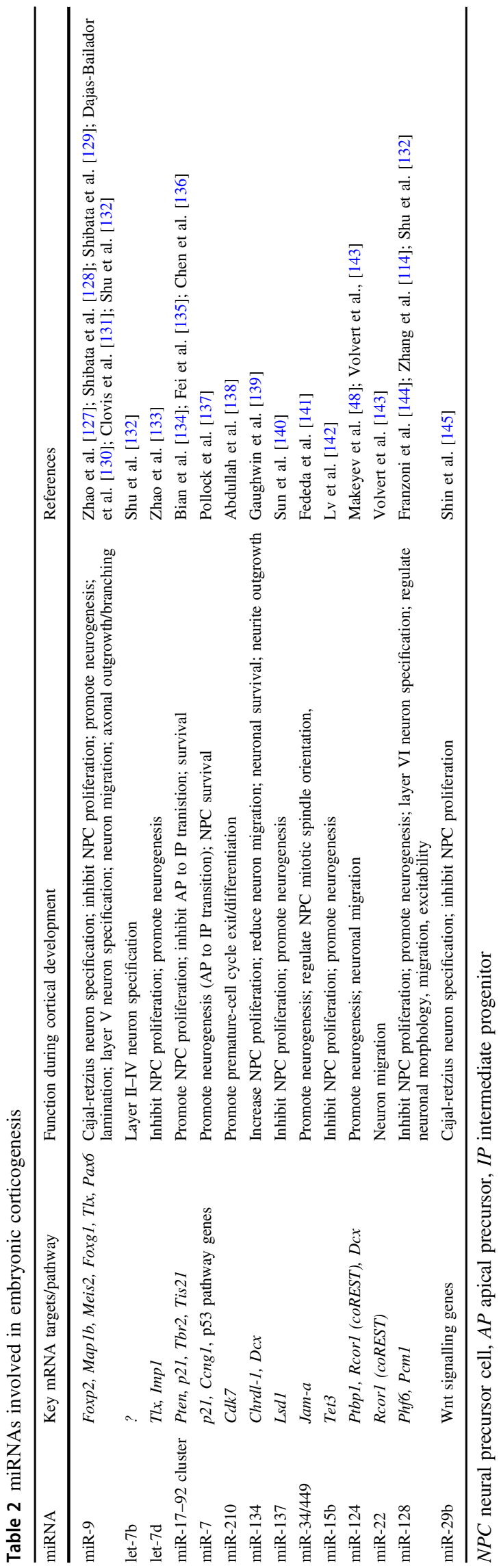

\section{mRNA localization}

RBPs involved in mRNA localization influence many cellular functions in the developing cortex including NPC proliferation, neurogenesis, and neuronal migration (Fig. 2a) (Table 1). During a neurogenic division, mRNAs encoding cell fate determinants are actively segregated within asymmetrically dividing RGPs (Fig. 2b) [49, 50]. For example, mRNA encoding the self-renewal protein CyclinD2 localizes at the basal end feet of RGPs where it is locally translated, a process dependent on transport elements within its $3^{\prime}$ UTR [51, 52]. During an asymmetric division, the daughter cell that inherits the basal process and CyclinD2 maintains its self-renewal capacity, while the other daughter cell begins differentiating (Fig. 2b) [51, 52]. How does mRNA transport occur within RGPs? By live imaging of embryonic organotypic brain slices, mRNAs were shown to be rapidly transported in basal processes toward the basal endfeet of RGPs where they were locally translated (Fig. 2b) [50]. This active transport was mediated by the RBP Fragile X Mental Retardation Protein (FMRP). In RGP basal endfeet, FMRP associates with mRNAs encoding signaling and cytoskeletal factors, many of which are associated with autism and neurogenesis [50].

Staufen2 (Stau2) is another RBP involved in mRNA localization. In RGPs, Stau2 forms a complex with the RBP Pumilio2 (Pum2) and the helicase Ddx1, and this complex asymmetrically segregates cell fate determinants such as Proxl into differentiating daughter cells (i.e., intermediate progenitors) during an asymmetric division (Fig. 2b) [49, 53]. Disruption of the complex by shRNA knockdown caused mislocalization and misexpression of Proxl, premature differentiation and depletion of RGPs [49, 53]. Collectively, these studies illustrate that regulatory mRNAs are segregated and actively transported in RGPs during asymmetric divisions to ensure appropriate cell fate decisions (Fig. 2b).

\section{mRNA stability and translation}

RBPs that regulate mRNA stability and translation play critical roles in NPC cell fate decisions (Fig. 2a) (Table 1). The RBP human antigen $\mathrm{R}(\mathrm{HuR})$ that interacts with $3^{\prime} \mathrm{UTR}$ to influence mRNA stability and translation [39], controls the association between translating polysomes and functionallyrelated mRNAs encoding transcriptional, translational, and neuronal layer-specific regulators in a developmental stagespecific manner [54]. HuR also controls the composition of translation initiation factors, elongation factors, and ribosomal proteins within polysomes. These alterations are functionally relevant, as HuR conditional knockout cortices are thinner with defects in neuronal differentiation, lamination, and corpus callosum formation [54]. HuR interacts with common and unique subsets of mRNAs during early and late neurogenesis, 


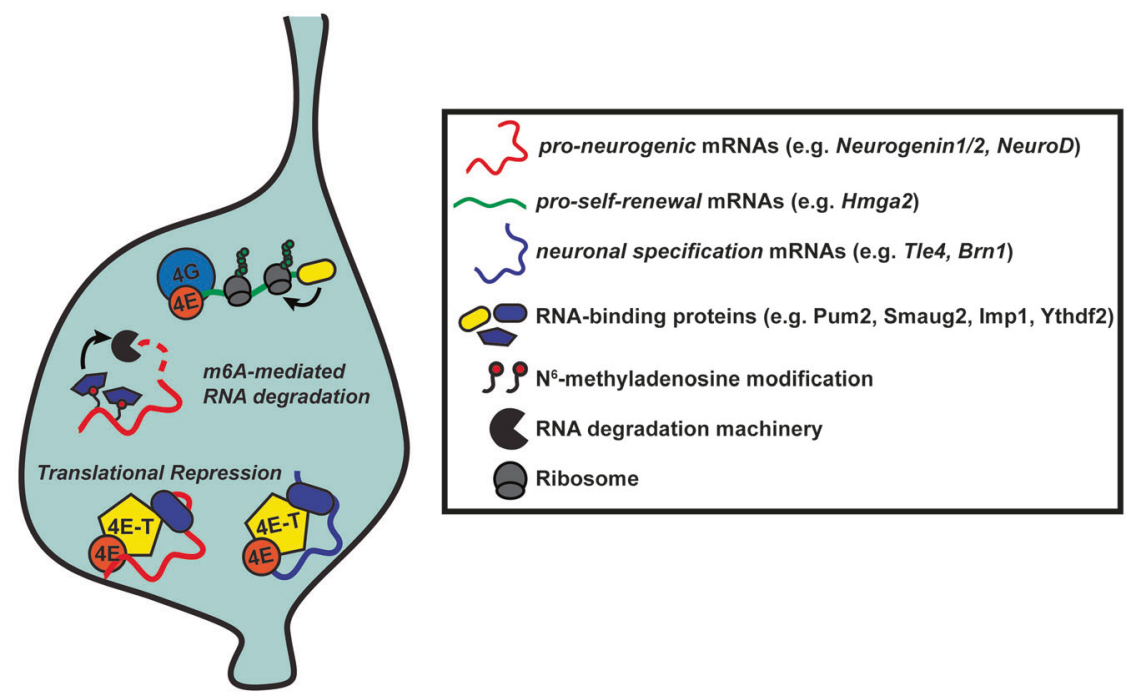

Transcriptionally primed neural precursor cell

Fig. 3 Transcriptional priming and posttranscriptional control in embryonic neural precursor cells (NPCs). Embryonic NPCs are transcriptionally primed to differentiate into diverse neuronal progeny, but maintained in an undifferentiated state until the appropriate time via posttranscriptional mechanisms. These mechanisms include degradation of m6A-modified mRNAs mediated by RNA-binding proteins (RBPs) such as Ythdf2 and translational repression by a Pum2-4E-T

suggesting that the mRNA targets of RBPs evolve as a function of time [55]. Another translational regulator that plays important roles during corticogenesis is FMRP. FMRP maintains RGPs in an undifferentiated state by repressing the RGP to IP transition [56]. This function is mediated in part by regulation of actin cytoskeletal organization at apical endfeet $[56,57]$.

\section{Transcriptional priming and posttranscriptional control}

Paradoxically, during cortical embryonic development, RGPs express mRNAs that maintain stem cell proliferation and self-renewal as well mRNAs that promote neurogenesis. How then do RGPs produce the correct number and subtype of neurons at the appropriate times during development? One mechanism is translational repression of mRNAs mediating neuronal differentiation (Fig. 3). In this regard, a repressive complex consisting of eIF4E and its binding partner 4E-T sequesters and represses proneurogenic mRNAs expressed in RGPs including $\mathrm{Neu}$ rogenin $1 / 2$ and NeuroD basic Helix-Loop-Helix transcription factor mRNAs (Fig. 3) [58]. Disruption of these complexes promoted neurogenesis, arguing that embryonic RGPs are transcriptionally primed (also called transcriptional prepatterning [59]) to generate neurons, with one or more translational repression complexes maintaining the stem cell state by silencing transcription translational repression complex. Silenced mRNAs include proneurogenic mRNAs (e.g., Neurogenin1/2, NeuroD1) and neuronal specification mRNAs (e.g., Brnl, Tle4). In addition to silencing proneurogenic mRNAs, RBPs (e.g., Imp1) can promote the stability and expression of pro-self-renewal mRNAs (e.g., Hmga2) to maintain NPCs in an undifferentiated state

factors that promote differentiation (Fig. 3). Presumably, external proneurogenic cues release this repression by asyet-undefined mechanisms, enabling translation of mRNAs mediating neurogenesis. Unlike most posttranscriptional regulators, the $4 \mathrm{E}-\mathrm{T}$ protein does not bind to mRNAs directly and must be recruited to target mRNAs via RBPs. Smaug2 is one RBP that mediates the interaction between 4E-T and target mRNAs such as Nanosl to maintain RGPs in an undifferentiated state [60]. Nanos1 is an RBP that reciprocally promotes neurogenesis, likely by repressing self-renewal genes. These findings suggest that appropriate neuronal differentiation involves both the translational derepression of proneurogenic mRNAs as well as the de novo repression of mRNAs required for stem cell maintenance [60].

A second way that the translation of proneurogenic proteins is maintained at low levels in transcriptionally-primed NPCs is via chemical modifications to mRNAs that trigger their decay (epitranscriptomics) (Fig. 3). Reversible $N^{6}$-methyladenosine $\left(\mathrm{m}^{6} \mathrm{~A}\right)$ modifications to mRNAs involved in cell cycle and neurogenesis results in their decay and controls the temporal progression of cortical neurogenesis [59]. These $\mathrm{m}^{6} \mathrm{~A}$-modified mRNAs are recognized, in part, by the RBP Ythdf2, which promotes their decay in the developing cortex (Fig. 3) [61]. As predicted if this is an important mechanism, Ythdf $2^{-1-}$ embryos display decreased cortical thickness owing to impaired NPC proliferation, neurogenesis, and neurite outgrowth [61]. 
Translational control mechanisms and priming not only regulate the timing of neurogenesis but also the types of neurons that are made [62, 63]. RGPs and IPs produce neurons that migrate basally to form the nascent cortical layers, with the earliest-born neurons populating the deepest layers and later-born neurons progressively populating more superficial layers. Subsequent to this neurogenic period, which occurs between E10.5 and E17.5 in the mouse, the same pool of RGPs generates glial cells. How is this timed cell genesis determined when RGPs coincidently express mRNAs encoding transcription factor specifiers for different types of neurons [62]? One mechanism involves selective translational repression of neuronal specifier mRNAs by 4E-T. 4E-T forms a complex with the RBP Pum2 in RGPs, and this complex associates with and silences the neuronal layer specifier mRNAs BrnI and Tle4 (Fig. 3). Disruption of these complexes during the period of superficial layer neurogenesis leads to aberrant translation of deep layer neuronal specifiers and misspecification of cortical neurons. [62] A second RBP involved in neuronal subtype specification is $\mathrm{HuD}$ [64]. $\mathrm{Hud}^{-1-}$ mice display a selective loss of Tle4-positive deep layer neurons, which the authors speculate may contribute to motor deficits observed in these mice, since corticospinal motor neurons are enriched in deeper layers [64]. A number of additional RBPs show cortical lamination deficits in loss-of-function experiments (Table 1). It is tempting to speculate that, like Pum2 and $\mathrm{HuD}$, these other RBPs control neuronal subtype specification by participating in repression complexes that selectively silence translation of neuronal specifier mRNAs.

Silencing of mRNAs (repression and/or decay) is not the only way that RBPs maintain NPC self-renewal and prevent premature differentiation. This is illustrated by the RBP Imp1 which is important for mRNA stability and translation [65]. Imp1 both translationally inhibits mRNAs associated with differentiation and increases the stability and expression of pro-self-renewal genes such as Hmga2 (Fig. 3). Consistent with this, cortex-specific Imp1 ablation resulted in reduced NPC self-renewal and accelerated neuronal and glial differentiation. Intriguingly, Imp1 expression is regulated by the miRNA Let-7, further highlighting the cross talk between RBP-and miRNA-mediated posttranscriptional control in the developing cortex [65].

These findings add to a growing body of work pointing to transcriptional priming of precursors in vivo, suggesting that RBPs are critical regulators of neuronal differentiation and subtype specification [59, 63]. This type of priming, which also occurs in embryonic and hematopoietic stem cells, makes sense from several perspectives [66, 67]. Transcriptional priming coupled with posttranscriptional control would enable the rapid regulation of neurogenesis and specification by extrinsic cues [58, 60, 62]. This 'priming' model is consistent with a single-cell RNA sequencing study of the developing cortex that showed a surprising degree of transcriptional expression overlap among RGPs, IPs, and neurons at different developmental stages with many cells coexpressing genes associated with two or even three different embryonic cortical cell types [63].

These studies highlight the importance of posttranscriptional control for ensuring the precise and timely genesis of neurons and neuronal subtypes during development (Tables 1 and 2). It should be kept in mind, however, that RBPs such as FMRP and Pum2 regulate multiple aspects of mRNA metabolism and have more than one cellular function during cortical neurogenesis (Table 1). Moreover, several of these RBPs play important roles in postmitotic neurons by regulating neuronal morphology, excitability, axonal growth, and synapse formation, processes that depend on local translation (Table 1) [68].

\section{Postnatal and adult V-SVZ neurogenesis}

There are two major regions where neurogenesis occurs in the postnatal and adult brain: the subgranular zone (SGZ) of the hippocampal dentate gyrus and the V-SVZ surrounding the lateral ventricles (Fig. $4 \mathrm{a}$ ). Here, we will provide a brief overview of V-SVZ neurogenesis before discussing the emerging role of posttranscriptional control. We guide the reader to the following review on SGZ neurogenesis [69].

\section{The V-SVZ niche}

Postnatal and adult NSCs (or B1 cells) reside within an epithelium known as the V-SVZ and are largely quiescent or very slowly dividing in vivo (Fig. 4a) [70]. Quiescent and activated (dividing) NSCs coexist in the V-SVZ and can interconvert in vitro [71]. Clonal lineage tracing approaches in vivo indicate that unlike embryonic RGPs, asymmetric divisions of adult NSCs are rare or do not occur [72]. Rather, they divide symmetrically to either self-renew or differentiate, with a greater probability of undergoing symmetric-consuming divisions leading to a decline in NSCs over time [72]. Activated V-SVZ NSCs give rise to transit-amplifying cells (or type $\mathrm{C}$ cells), which divide symmetrically three to four times before generating neuroblasts (or type A cells) (Fig. 4a, c) [70, 73]. Neuroblasts migrate along the rostral migratory stream to the olfactory bulb where they differentiate into various subtypes of interneurons [73, 74], integrating into the existing olfactory bulb circuitry, and influencing the plasticity of olfactoryrelated behaviors [73]. Retroviral fate-mapping of V-SVZ NSCs showed that in both healthy and demyelinating conditions, NSCs can generate oligodendrocytes destined for the corpus callosum where they myelinate axons [75]. 


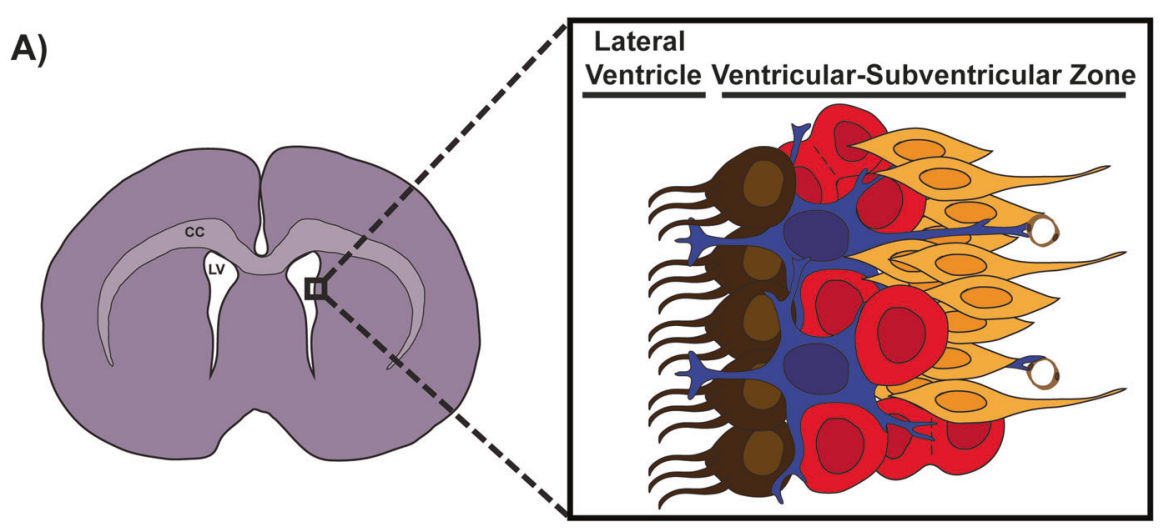

B)
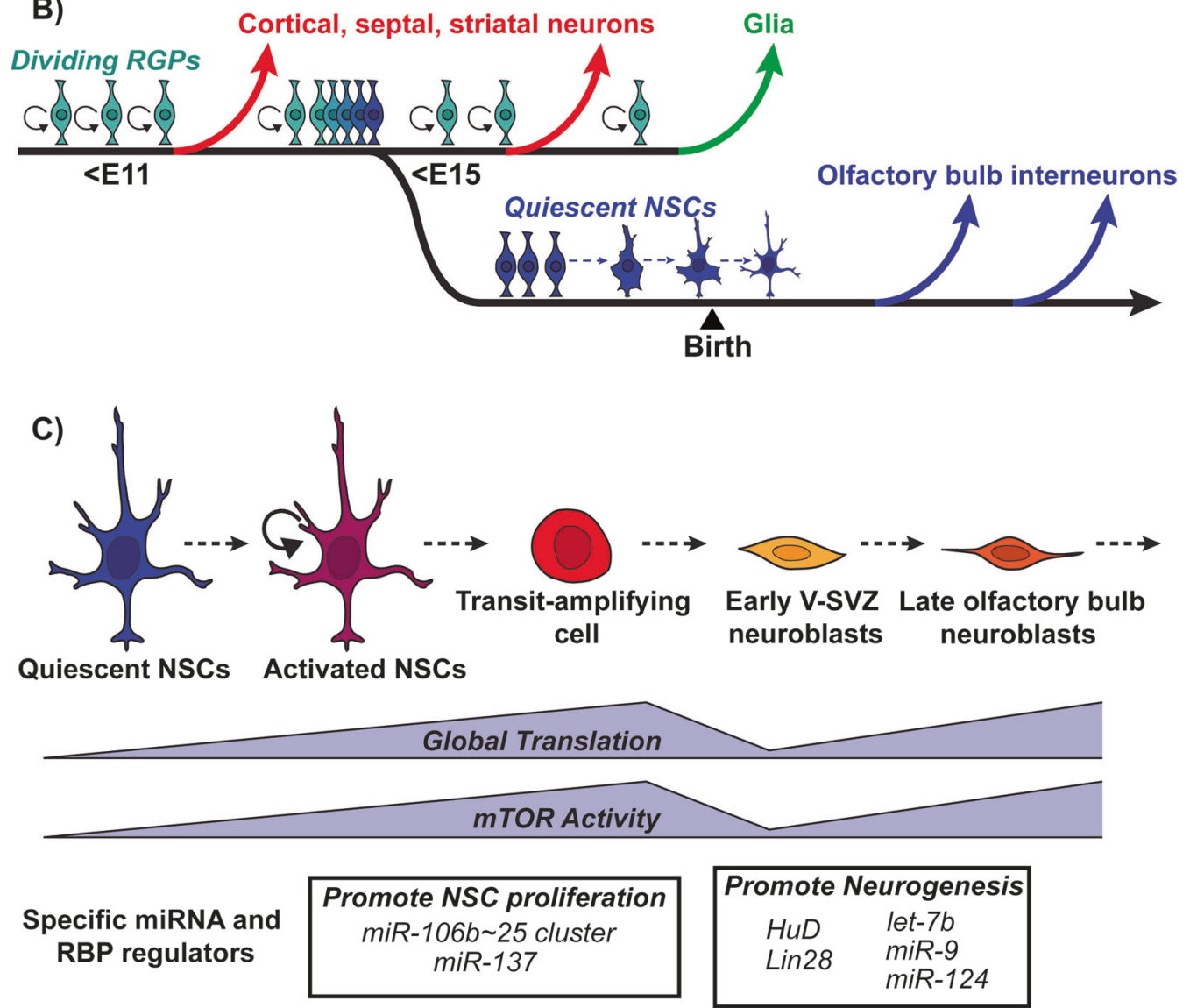

Fig. 4 The postnatal/adult ventricular-subventricular zone (V-SVZ) niche. a Coronal section of the postnatal/adult brain. Lining the lateral ventricles of the postnatal/adult brain is a cell dense area known as the V-SVZ. The V-SVZ contains several cell types: ependymal cells (brown), neural stem cells (blue), transit amplifying cells (red), and early neuroblasts (orange). CC corpus callosum, LV lateral ventricle. b A subpopulation of radial glial precursors (RGPs) that produce cortical, septal, striatal neurons, and glia embryonically, becomes quiescent between $\sim \mathrm{E} 13$ and E15. These cells remain quiescent until they are activated during adulthood and generate olfactory bulb interneurons [77]. The transition to quiescence is indicated in the schematic by the shift in the color of RGPs from light to dark blue. $\mathbf{c}$ In the V-SVZ, quiescent NSCs (blue) become activated (purple) and give rise to transit amplifying cells (red) before generating early V-SVZ neuroblasts (yellow), which migrate toward the olfactory bulb. In the olfactory bulb, these late neuroblasts (orange) complete their differentiation into various subtypes of interneurons. Global protein translation and mTOR activity increase as quiescent NSCs become activated and generate transit amplifying cells, but then drops in early neuroblasts before increasing again as early neuroblasts mature into late OB neuroblasts [82]. miRNAs and RBPs regulate the translation of specific mRNAs to either promote V-SVZ NSC proliferation or promote neurogenesis 
V-SVZ NSCs also generate astrocytes following a photothrombotic ischemic cortical injury [76].

\section{Intrinsic and extrinsic regulation of postnatal/adult V-SVZ neurogenesis}

Adult V-SVZ NSCs, which generate inhibitory interneurons and glia, are derived from three embryonic sources. The majority derive from the ganglionic eminence, and the remainder from the embryonic cortex and septum (Fig. 4b). Lineage tracing has shown that embryonic RGPs from these three origins give rise to distinct postnatal V-SVZ NSC compartments, and ultimately generate different subtypes of olfactory bulb interneurons depending on their location along the anterior-posterior and dorsal-ventral axes of the V-SVZ [70, 73, 77]. In addition to generating interneuron subtypes, there is emerging evidence that at least some of the cortical RGPs that produce excitatory neurons during embryogenesis switch to generating inhibitory interneurons postnatally (Fig. 4b), even though they maintain their transcriptional core identity as they make this switch $[63,77]$. Thus, one of the major questions in the field is how the same population of adult NSCs is regulated to generate these diverse populations of neurons. V-SVZ NSCs reside in a specialized niche rich in extracellular cues, including factors that originate from the NSCs themselves, surrounding niche cell types such as ependymal cells, vascular cells, astrocytes, microglia, the more committed progeny of NSCs, and the CSF and circulation. These factors likely regulate the activity of transcription and epigenetic factors important for the regulation of NSC maintenance, differentiation, and cell fate determination. For reviews on intrinsic and extrinsic regulation of V-SVZ neurogenesis, we guide the reader to several reviews $[70,73,74]$.

\section{Going beyond transcriptional and epigenetic control in the postnatal/adult V- SVZ}

\section{Global control of protein translation}

Low protein synthesis is a general feature of the stem cell state in embryonic, hematopoietic, hair follicle, muscle, and neural stem cells [25]. In these cells, inhibition of protein synthesis tends to increase self-renewal while activation of protein synthesis promotes the onset of differentiation [25]. Consistent with this, ribosomal genes are transcriptionally upregulated and protein synthesis is increased as adult NSCs transition from a quiescent to activated (dividing) state, and mTORC1, an inducer of global protein synthesis, is activated when NSCs transition to transit-amplifying cells (Fig. 4c) [78-80]. Moreover, hyperactivating mTORC1 in neonatal
V-SVZ NSCs results in depletion of NSCs (i.e., reduced selfrenewal) and increased differentiation into transit-amplifying cells and neuroblasts, while reducing mTORC1 activity in NSCs prevents their differentiation and decreases neuroblast formation [81]. This phenotype was recapitulated in young adult mice in a follow-up study; elevating mTORC1 activity in slowly-dividing NSCs robustly increased transit-amplifying cells and neuroblasts [80].

How does mTORC1 activity control the NSC to neuron transition? Using a RiboTag approach to profile the transcriptome (total mRNA) and translatome (ribosome-bound mRNA) in quiescent NSCs, activated NSCs, early neuroblasts (isolated from SVZ), and late neuroblasts (isolated from the olfactory bulb), Baser et al. captured the overall state of transcription and translation as stem cells transitioned to newly-born neurons [82]. Global translation increased from the NSC to transit amplifying cell stage, but then dropped in early neuroblasts before increasing again as early neuroblasts matured to late olfactory bulb neuroblasts (Fig. 4c). The decrease in translation in early neuroblasts was attributable to a decrease in mTORC1-mediated translational activity (Fig. 4c). The translation of the stem cell maintenance factor Sox2 was repressed at this stage, suggesting that appropriate progression along the differentiation pathway involves the repression of stem cell maintenance factors at the early neuroblast stage [82]. One interpretation of these data is that translational repression mechanisms keep quiescent NSCs in an undifferentiated state, and that derepression needs to occur to trigger the switch to activation and early differentiation. However, as described above, once cells are on a differentiation trajectory, additional selective translational repression of stemness genes regulated for example by RBPs and miRNAs are required to ensure that they differentiate at the right time and place (Fig. 4c).

In addition to the global regulation of translation, several specific miRNAs and RBPs control V-SVZ NSC self-renewal and neurogenesis (Fig. 4c; Table 3). For example, miR-124 promotes neuronal differentiation by repressing $\operatorname{Sox} 9$ mRNA, which promotes NSC self-renewal in neuroblasts [83]. miR137 , in contrast, inhibits differentiation and promotes NSC proliferation by repressing the histone methyltransferase $E z h 2$, highlighting the interplay between posttranscriptional control and epigenetic mechanisms (Fig. 4c) [84]. miRNAmediated repression also controls the dorsal-ventral regionalization of V-SVZ NSCs and consequently, interneuron subtype specification [85]. In this regard, Pax6 protein expression is restricted to the dorsal V-SVZ, while Pax6 mRNA is expressed all along the dorsal-ventral axis. This restricted expression pattern is due to miR-7a-mediated translational repression of Pax6 mRNA in the ventral V-SVZ [85]. Inhibition of miR-7a results in translation of Pax6 mRNA in ventral regions and increased production of dopaminergic neurons in the olfactory bulb [85]. Together, these findings 
Table 3 miRNAs and RBPs involved in postnatal/adult V-SVZ Neurogenesis

\begin{tabular}{llll}
\hline miRNA & $\begin{array}{l}\text { Key mRNA targets/ } \\
\text { pathway }\end{array}$ & Function in postnatal/adult V-SVZ & References \\
\hline let-7b & Hmga2, Tlx, CyclinD1 & Promote neurogenesis; inhibit NSC proliferation & $\begin{array}{l}\text { Nishino et al. [146]; Zhao et al. } \\
\text { [147] }\end{array}$ \\
miR-7a & Pax6 & Dopaminergic neuron subtype specification & De Chevigny et al. [85] \\
miR-9 & Foxo1 (predicted) & Promote neurogenesis & Kim et al. [148] \\
miR-19 & Rabgef2 & Neuronal migration & Han et al. [149] \\
miR-124 & Sox9 & Promote neurogenesis; inhibit gligogenesis (astrocytes) & Cheng et al. [83] \\
miR-137 & Ezh2 & Promote NSC proliferation; inhibit neurogenesis & Szulwach et al. [84] \\
miR-25 (miR-106b 25) & Foxo3 (predicted) & Promote NSC proliferation & Brett et al. [150] \\
cluster & & & Akamatsu et al. [105]; Wang \\
RNA-binding protein & & Inhibit NSC proliferation;promote neurogenesis & et al. [151] \\
HuD & Satb1 & Promote neuroblast formation (long term depletion of & Romer-Seibert et al. [152] \\
Lin28 & Let-7 & OB neurons and astrocytes) & Lampasona et al. [156] \\
Enrnpab & Evs8 & SVZ cell migration &
\end{tabular}

NSC neural stem cell, $O B$ olfactory bulb

argue that miRNAs play important roles in NSC self-renewal, differentiation, regionalization, and specification of particular interneuron subtypes.

A recent single-cell RNA sequencing study of adult V-SVZ NSCs identified a subset of activated NSCs that express GABAergic neuronal differentiation genes such as Dlxl and Dlx2, suggesting that a subpopulation of NSCs may be primed for GABAergic differentiation [58, 86]. This raises the intriguing possibility that posttranscriptional mechanisms control the onset of differentiation in an analogous fashion to embryonic RGPs [58, 60, 62]. This avenue of research, still at an early stage, should identify the RBPs, miRNAs, translational regulators, and their functional roles at various stages of postnatal V-SVZ neurogenesis (Table 3) [25].

\section{An integrated network of posttranscriptional control}

How do these RBPs, miRNAs, and other translational regulators fit within the larger landscape of global posttranscriptional control? It is now clear that many of these factors are expressed in a temporally dynamic and cell-type specific manner throughout corticogenesis [32, 35-37]. Moreover, evidence from RNA immunoprecipitation (RIP) and transcriptome analyses suggest that these regulators share partially overlapping mRNA targets. For instance, HuR and FMRP share target mRNAs in the developing cortex, and Pum1/2 share targets with FMRP in the brain [55, 87]. 4E-T interacts with and shares mRNA targets with the RBPs Pum2 and Smaug2 [58, 60, 62]. Interestingly, the RBP Lin28a promotes NPC proliferation in a manner dependent on its interaction with Imp1, suggesting that there are also important functional interactions between RBPs [88]. Together, these findings point to an extensive network of posttranscriptional control, in which RBPs, miRNAs, and other translational regulators coordinately control the expression of partially overlapping, functionally important mRNAs [89]. This partial redundancy makes the system robust and ensures that perturbations in any one component would not necessarily lead to massive, irreversible alterations in gene expression [89]. Similar networks exist in the model organisms $S$. cerevisiae and D. melanogaster, and in the developing cortex these networks are now being validated by mining RIP datasets for overlapping mRNA targets of individual RBPs [31]. Moreover, as described previously, posttranscriptional regulators are themselves the target of posttranscriptional control. Thus, as others have argued, this network with overlapping targets and multiple feedback loops provides a "self-limiting" and "self-sustaining" balance of RBPs, lending further resilience to posttranscriptional control networks [31].

\section{Upstream regulation of the posttranscriptional machinery}

As discussed above, NPC niches are rich in extrinsic cues that regulate their proliferation, differentiation, and cell fate specification, and it is therefore likely that environmentallydriven signaling pathways regulate RBP expression and/or interactions with target mRNAs [20]. For example, Wnt1 signaling, which enhances embryonic NPC maintenance and proliferation, promotes Imp1 expression during 
cortical development [65]. As a second example, timed Wnt3 secretion from thalamocortical axons around midneurogenesis regulates both the composition of ribosomal proteins and the subset of mRNAs that are associated with polysomes [34]. Wnt3 promoted Foxp 2 mRNA association with and translation in polysomes via regulation of its $3^{\prime} \mathrm{UTR}$, and conditional ablation of thalamic Wnt3 impaired the specification of Foxp2-positive deep layer neurons [34]. How then might these extrinsic cues feed onto the posttranscriptional machinery? Many RBPs contain multiple consensus phosphorylation sites, suggesting that they can be regulated by phosphorylation [90]. In this regard, HuR phosphorylation is important for regulating its translational control of the autism-associated mRNAs Foxp1 and Foxp2 in the developing cortex [55]. Moreover, RBP interactions with target mRNAs are regulated by phosphorylation in response to growth factor stimulation in other contexts [91]. Thus, receptor-mediated phosphorylation of RBPs likely provides one mechanism for rapidly and reversibly altering the translation of subsets of mRNAs that regulate NPC biology.

\section{Concluding remarks}

The ability to rapidly modulate protein expression levels is crucial for neural stem cells, which must integrate a multitude of cues to ensure the genesis of the right cells at the right time, while at the same time maintaining the requisite levels of selfrenewal. These decisions require both the fast induction of particular lineage programs and the rapid turning off of programs that specify alternative fates. Furthermore, differentiation involves extensive rearrangements in morphology and increased metabolic requirements, further highlighting the need for rapid control of protein synthesis [78, 92]. Posttranscriptional regulation plays multiple roles along these differentiation trajectories, regulating the onset of differentiation, stem cell maintenance, and consolidation of the differentiated phenotype [58, 60, 62, 82, 83].

Given the emerging importance of posttranscriptional control in rodents, could analogous mechanisms be operating in the developing human cortex and partially underlie its increased expansion and complexity? In support of this idea, numerous miRNAs are expressed in the developing macaque but not mouse cortex, and are differentially expressed in the VZ and outer SVZ where they regulate cell cycle and neurogenic genes [93]. Moreover, extensive changes in $3^{\prime}$ and $5^{\prime}$-UTR-mediated translation occur as human ES cells differentiate into cortical neurons [94]. Furthermore, all of the RBPs mentioned in this review have human and nonhuman primate orthologs, and these RBPs are highly expressed during the human neurogenic period [95]. RBPs involved in alternative splicing have likely contributed to the increased complexity of the human brain by amplifying the protein diversity of the transcriptome. In support of this idea, the human brain expresses more alternatively spliced mRNAs than any other tissue [40].

Several RBPs and miRNAs have been causally implicated in the pathogenesis of human neurodevelopmental and neurodegenerative disorders including Fragile-X-syndrome, autism spectrum disorder, spinal muscular atrophy, amyotrophic lateral sclerosis, and frontotemporal dementia [96]. Dysregulated activity and expression of RBPs and miRNAs are also causally associated with glioblastoma and medulloblastoma [97]. Therefore, as future work elucidates their roles during rodent and ultimately human cortical development, this should provide valuable insights into both normal and pathological brain function [27, 96, 97].

Acknowledgements We apologize to all those whose work could not be included in this review due to space constraints. This work was funded by grants from the Canadian Institutes for Health Research to FDM and Medicine by Design/Canadian First Research Excellence Fund to DRK and FDM. SKZ was funded by the Canadian Institutes for Health Research.

\section{Compliance with ethical standards}

Conflict of interest The authors declare that they have no conflict of interest.

Publisher's note Springer Nature remains neutral with regard to jurisdictional claims in published maps and institutional affiliations.

\section{References}

1. Jabaudon D. Fate and freedom in developing neocortical circuits. Nat Commun. 2017;8:16042.

2. Juric-Sekhar G, Hevner RF. Malformations of cerebral cortex development: molecules and mechanisms. Annu Rev Pathol . 2019;14:293-318.

3. Gao P, Postiglione MP, Krieger TG, Hernandez L, Wang C, Han $\mathrm{Z}$, et al. Deterministic progenitor behavior and unitary production of neurons in the neocortex. Cell. 2014;159:775-88.

4. Greig LC, Woodworth MB, Galazo MJ, Padmanabhan H, Macklis JD. Molecular logic of neocortical projection neuron specification, development and diversity. Nat Rev Neurosci. 2013;14:755-69.

5. Noctor SC, Flint AC, Weissman TA, Dammerman RS, Kriegstein AR. Neurons derived from radial glial cells establish radial units in neocortex. Nature. 2001;409:714-20.

6. Haubensak W, Attardo A, Denk W, Huttner WB. Neurons arise in the basal neuroepithelium of the early mammalian telencephalon: a major site of neurogenesis. Proc Natl Acad Sci USA. 2004;101:3196-201.

7. Fietz SA, Kelava I, Vogt J, Wilsch-Bräuninger M, Stenzel D, Fish JL, et al. OSVZ progenitors of human and ferret neocortex are epithelial-like and expand by integrin signaling. Nat Neurosci. 2010;13:690-9.

8. Molyneaux BJ, Goff LA, Brettler AC, Chen HH, Brown JR, Hrvatin S, et al. DeCoN: Genome-wide analysis of invivo transcriptional dynamics during pyramidal neuron fate selection in neocortex. Neuron. 2015;85:275-88. 
9. Johnson MB, Walsh CA. Cerebral cortical neuron diversity and development at single-cell resolution. Curr Opin Neurobiol. 2017;42:9-16.

10. Toma K, Hanashima C. Switching modes in corticogenesis: mechanisms of neuronal subtype transitions and integration in the cerebral cortex. Front Neurosci. 2015;9:274.

11. Kawaguchi A. Temporal patterning of neocortical progenitor cells: how do they know the right time? Neurosci Res. 2019;138:3-11.

12. Frantz GD, McConnell SK. Restriction of late cerebral cortical progenitor cells to an upper-layer fate. Neuron. 1996;17:55-61.

13. Oberst $P$, Fièvre $S$, Baumann $N$, Concetti $C$, Bartolini G, Jabaudon D. Temporal plasticity of apical progenitors in the developing mouse neocortex. Nature. 2019. [Epub ahead of print].

14. Belgard TG, Marques AC, Oliver PL, Abaan HO, Sirey TM, Hoerder-Suabedissen A, et al. A transcriptomic atlas of mouse neocortical layers. Neuron. 2011;71:605-16.

15. Oishi K, Aramaki M, Nakajima K. Mutually repressive interaction between Brn1/2 and Rorb contributes to the establishment of neocortical layer $2 / 3$ and layer 4. Proc Natl Acad Sci USA. 2016;1:201515949.

16. Yoon KJ, Vissers C, Ming GL, Song H. Epigenetics and epitranscriptomics in temporal patterning of cortical neural progenitor competence. J Cell Biol. 2018;217:1901-14.

17. Sanosaka T, Imamura T, Hamazaki N, Chai MC, Igarashi K, Ideta-Otsuka M, et al. DNA methylome analysis identifies transcription factor-based epigenomic signatures of multilineage competence in neural stem/progenitor cells. Cell Rep. 2017;20:2992-3003.

18. Taverna E, Götz M, Huttner WB. The cell biology of neurogenesis: toward an understanding of the development and evolution of the neocortex. Annu Rev Cell Dev Biol. 2014;30:465-502.

19. Hardwick LJA, Ali FR, Azzarelli R, Philpott A. Cell cycle regulation of proliferation versus differentiation in the central nervous system. Cell Tissue Res. 2015;359:187-200.

20. Yuzwa SA, Yang G, Borrett MJ, Clarke G, Cancino GI, Zahr SK, et al. Proneurogenic ligands defined by modeling developing cortex growth factor communication networks. Neuron. 2016;91:988-1004.

21. Oishi K, Nakajima K. Subtype specification of cerebral cortical neurons in their immature stages. Neurochem Res. 2018;43:238-44.

22. Liu Y, Beyer A, Aebersold R. On the dependency of cellular protein levels on mRNA abundance. Cell. 2016;165:535-50.

23. Tahmasebi S, Amiri M, Sonenberg N. Translational control in stem cells. Front Genet. 2019;9:709.

24. Kristensen AR, Gsponer J, Foster LJ. Protein synthesis rate is the predominant regulator of protein expression during differentiation. Mol Syst Biol. 2013;9:689.

25. Teixeira FK, Lehmann R. Translational control during developmental transitions. Cold Spring Harb Perspect Biol. 2018;11: a032987.

26. Jovanovic M, Rooney MS, Mertins P, Przybylski D, Chevrier N, Satija R, et al. Dynamic profiling of the protein life cycle in response to pathogens. Science. 2015;347:1259038.

27. Lennox AL, Mao H, Silver DL. RNA on the brain: emerging layers of post-transcriptional regulation in cerebral cortex development. Wiley Interdiscip Rev Dev Biol. 2017;7:e290.

28. Gerstberger S, Hafner M, Tuschl T. A census of human RNAbinding proteins. Nat Rev Genet. 2014;15:829-45.

29. Kozomara A, Birgaoanu M, Griffiths-Jones S. MiRBase: from microRNA sequences to function. Nucleic Acids Res. 2019;47: D155-62.
30. Lambert SA, Jolma A, Campitelli LF, Das PK, Yin Y, Albu M, et al. The human transcription factors. Cell. 2018;172:650-65.

31. Keene JD. RNA regulons: coordination of post-transcriptional events. Nat Rev Genet. 2007;8:533-43.

32. DeBoer EM, Kraushar ML, Hart RP, Rasin MR. Posttranscriptional regulatory elements and spatiotemporal specification of neocortical stem cells and projection neurons. Neuroscience 2013;248:499-528.

33. McKee AE, Minet E, Stern C, Riahi S, Stiles CD, Silver PA . A genome-wide in situ hybridization map of RNA-binding proteins reveals anatomically restricted expression in the developing mouse brain. BMC Dev Biol. 2005;5:14.

34. Kraushar ML, Viljetic B, Wijeratne HRS, Thompson K, Jiao X, Pike JW, et al. Thalamic WNT3 secretion spatiotemporally regulates the neocortical ribosome signature and mRNA translation to specify neocortical cell subtypes. J Neurosci. 2015;35:10911-26.

35. Nowakowski TJ, Rani N, Golkaram M, Zhou HR, Alvarado B, Huch K, et al. Regulation of cell-type-specific transcriptomes by microRNA networks during human brain development. Nat Neurosci. 2018;21:1784-92.

36. Volvert M-L, Rogister F, Moonen G, Malgrange B, Nguyen L. MicroRNAs tune cerebral cortical neurogenesis. Cell Death Differ. 2012;19:1573-81.

37. Krichevsky AM, King KS, Donahue CP, Khrapko K, Kosik KS. A microRNA array reveals extensive regulation of microRNAs during brain development. RNA. 2003;9:1274-81.

38. Rajman M, Schratt G. MicroRNAs in neural development: from master regulators to fine-tuners. Development. 2017; 144:2310-22.

39. Pilaz LJ, Silver DL. Post-transcriptional regulation in corticogenesis: how RNA-binding proteins help build the brain. Wiley Interdiscip Rev RNA. 2015. https://doi.org/10.1002/wrna.1289.

40. Johnson MB, Kawasawa YI, Mason CE, Krsnik Ž, Coppola G, Bogdanović D, et al. Functional and evolutionary insights into human brain development through global transcriptome analysis. Neuron. 2009;62:494-509.

41. Ayoub AE, Oh S, Xie Y, Leng J, Cotney J, Dominguez MH, et al. Transcriptional programs in transient embryonic zones of the cerebral cortex defined by high-resolution mRNA sequencing. Proc Natl Acad Sci USA. 2011;108:14950-5.

42. Dillman AA, Hauser DN, Gibbs JR, Nalls MA, McCoy MK, Rudenko IN, et al. mRNA expression, splicing and editing in the embryonic and adult mouse cerebral cortex. Nat Neurosci. 2013;16:499-506.

43. Yan Q, Weyn-Vanhentenryck SM, Wu J, Sloan SA, Zhang Y, Chen K, et al. Systematic discovery of regulated and conserved alternative exons in the mammalian brain reveals NMD modulating chromatin regulators. Proc Natl Acad Sci USA. 2015;112:3445-50.

44. Zhang X, Chen MH, Wu X, Kodani A, Fan J, Doan R, et al. Cell-type-specific alternative splicing governs cell fate in the developing cerebral cortex. Cell. 2016;166:1147-.e15.

45. Weyn-Vanhentenryck SM, Feng H, Ustianenko D, Duffié R, Yan Q, Jacko M, et al. Precise temporal regulation of alternative splicing during neural development. Nat Commun. 2018;9:2189.

46. Shibasaki T, Tokunaga A, Sakamoto R, Sagara H, Noguchi S, Sasaoka T, et al. PTB deficiency causes the loss of adherens junctions in the dorsal telencephalon and leads to lethal hydrocephalus. Cereb Cortex. 2013;23:1824-35.

47. Ramos AD, Andersen RE, Liu SJ, Nowakowski TJ, Hong SJ, Gertz CC, et al. The long noncoding RNA Pnky regulates neuronal differentiation of embryonic and postnatal neural stem cells. Cell Stem Cell. 2015;16:439-47.

48. Makeyev EV, Zhang J, Carrasco MA, Maniatis T. The microRNA miR-124 promotes neuronal differentiation by triggering 
brain-specific alternative pre-mRNA splicing. Mol Cell. 2007;27:435-48.

49. Vessey JP, Amadei G, Burns SE, Kiebler MA, Kaplan DR, Miller FD. An asymmetrically localized Staufen2-dependent RNA complex regulates maintenance of mammalian neural stem cells. Cell Stem Cell. 2012;11:517-28.

50. Pilaz LJ, Lennox AL, Rouanet JP, Silver DL. Dynamic mRNA transport and local translation in radial glial progenitors of the developing brain. Curr Biol. 2016;26:3383-92.

51. Tsunekawa Y, Britto JM, Takahashi M, Polleux F, Tan SS, Osumi N. Cyclin D2 in the basal process of neural progenitors is linked to non-equivalent cell fates. EMBO J. 2012;31:1879-92.

52. Tsunekawa Y, Kikkawa T, Osumi N. Asymmetric inheritance of Cyclin D2 maintains proliferative neural stem/progenitor cells: a critical event in brain development and evolution. Dev Growth Differ. 2014;56:349-57.

53. Kusek G, Campbell M, Doyle F, Tenenbaum SA, Kiebler M, Temple S. Asymmetric segregation of the double-stranded RNA binding protein Staufen2 during mammalian neural stem cell divisions promotes lineage progression. Cell Stem Cell. 2012;11:505-16.

54. Kraushar ML, Thompson K, Wijeratne HRS, Viljetic B, Sakers $\mathrm{K}$, Marson JW, et al. Temporally defined neocortical translation and polysome assembly are determined by the RNA-binding protein $\mathrm{Hu}$ antigen R. Proc Natl Acad Sci USA. 2014;111: E3815-24.

55. Popovitchenko T, Thompson K, Viljetic B, Jiao X, Kontonyiannis DL, Kiledjian M, et al. The RNA binding protein HuR determines the differential translation of autism-associated FoxP subfamily members in the developing neocortex. Sci Rep. 2016;6:28998

56. Saffary R, Xie Z. FMRP regulates the transition from radial glial cells to intermediate progenitor cells during neocortical development. J Neurosci. 2011;31:1427-39.

57. Tervonen TA, Louhivuori V, Sun X, Hokkanen ME, Kratochwil $\mathrm{CF}$, Zebryk $\mathrm{P}$, et al. Aberrant differentiation of glutamatergic cells in neocortex of mouse model for fragile $\mathrm{X}$ syndrome. Neurobiol Dis. 2009;33:250-9.

58. Yang G, Smibert CA, Kaplan DR, Miller FD. An eIF4E1/4E-T complex determines the genesis of neurons from precursors by translationally repressing a proneurogenic transcription program. Neuron. 2014;84:723-39.

59. Yoon K-J, Ringeling FR, Vissers C, Jacob F, Pokrass M, Jimenez-Cyrus D et al. Temporal control of mammalian cortical neurogenesis by $\mathrm{m}^{6} \mathrm{~A}$ methylation. Cell. 2017. https://doi.org/10. 1016/j.cell.2017.09.003.

60. Amadei G, Zander MA, Yang G, Dumelie JG, Vessey JP, Lipshitz HD, et al. A smaug2-based translational repression complex determines the balance between precursor maintenance versus differentiation during mammalian neurogenesis. J Neurosci. 2015;35:15666-81.

61. Li M, Zhao X, Wang W, Shi H, Pan Q, Lu Z, et al. Ythdf2mediated $\mathrm{m}^{6} \mathrm{~A}$ mRNA clearance modulates neural development in mice. Genome Biol. 2018;19:69.

62. Zahr SK, Yang G, Kazan H, Borrett MJ, Yuzwa SA, Voronova A, et al. A translational repression complex in developing mammalian neural stem cells that regulates neuronal specification. Neuron. 2018;97:520-37.

63. Yuzwa SA, Borrett MJ, Innes BT, Voronova A, Ketela T, Kaplan DR, et al. Developmental emergence of adult neural stem cells as revealed by single-cell transcriptional profiling. Cell Rep. 2017;21:3970-86.

64. DeBoer EM, Azevedo R, Vega TA, Brodkin J, Akamatsu W, Okano $\mathrm{H}$, et al. Prenatal deletion of the RNA-binding protein $\mathrm{HuD}$ disrupts postnatal cortical circuit maturation and behavior. $\mathbf{J}$ Neurosci. 2014;34:3674-86.
65. Nishino J, Kim S, Zhu Y, Zhu H, Morrison SJ. A network of heterochronic genes including Imp1 regulates temporal changes in stem cell properties. Elife. 2013;2:e00924.

66. Hu M, Krause D, Greaves M, Sharkis S, Dexter M, Heyworth C, et al. Multilineage gene expression precedes commitment in the hemopoietic system. Genes Dev. 1997;11:774-85.

67. Efroni S, Duttagupta R, Cheng J, Dehghani H, Hoeppner DJ, Dash C, et al. Global transcription in pluripotent embryonic stem cells. Cell Stem Cell. 2008;2:437-47.

68. Van Driesche SJ, Martin KC. New frontiers in RNA transport and local translation in neurons. Dev Neurobiol. 2018;78:331-9.

69. Gonçalves JT, Schafer ST, Gage FH. Adult neurogenesis in the hippocampus: from stem cells to behavior. Cell. 2016;167:897-914.

70. Obernier K, Alvarez-Buylla A. Neural stem cells: origin, heterogeneity and regulation in the adult mammalian brain. Development. 2019;146:dev156059.

71. Codega P, Silva-Vargas V, Paul A, Maldonado-Soto AR, DeLeo AM, Pastrana E, et al. Prospective identification and purification of quiescent adult neural stem cells from their in vivo niche. Neuron. 2014;82:545-59.

72. Kirsten Obernier A, Cebrian-Silla A, Thomson M, Rodas Rodriguez J, Manuel Garcia-Verdugo J, Alvarez-Buylla Correspondence A. Adult neurogenesis is sustained by symmetric selfrenewal and differentiation. Cell Stem Cell. 2018;22:221-34.

73. Lim DA, Alvarez-Buylla A. The adult ventricular-subventricular zone (V-SVZ) and olfactory bulb (OB) neurogenesis. Cold Spring Harb Perspect Biol. 2016;8:a018820.

74. Bond AM, Ming GL, Song H. Adult mammalian neural stem cells and neurogenesis: five decades later. Cell Stem Cell. 2015;17:385-95.

75. Menn B, Garcia-Verdugo JM, Yaschine C, Gonzalez-Perez O, Rowitch D, Alvarez-Buylla A. Origin of oligodendrocytes in the subventricular zone of the adult brain. J Neurosci. 2006;26:7907-18.

76. Benner EJ, Luciano D, Jo R, Abdi K, Paez-Gonzalez P, Sheng H, et al. Protective astrogenesis from the SVZ niche after injury is controlled by Notch modulator Thbs4. Nature. 2013;497:369-73.

77. Fuentealba LC, Rompani SB, Parraguez JI, Obernier K, Romero R, Cepko CL, et al. Embryonic origin of postnatal neural stem cells. Cell. 2015;161:1644-55.

78. Llorens-Bobadilla E, Zhao S, Baser A, Saiz-Castro G, Zwadlo K, Martin-Villalba A. Single-cell transcriptomics reveals a population of dormant neural stem cells that become activated upon brain injury. Cell Stem Cell. 2015;17:329-40.

79. Paliouras GN, Hamilton LK, Aumont A, Joppe SE, BarnabeHeider F, Fernandes KJL. Mammalian target of rapamycin signaling is a key regulator of the transit-amplifying progenitor pool in the adult and aging forebrain. J Neurosci. 2012;32:15012-26.

80. Mahoney C, Feliciano DM, Bordey A, Hartman NW. Switching on mTORC1 induces neurogenesis but not proliferation in neural stem cells of young mice. Neurosci Lett. 2016;614:112-8.

81. Hartman NW, Lin TV, Zhang L, Paquelet GE, Feliciano DM, Bordey A. mTORC1 targets the translational repressor 4E-BP2, but Not S6 kinase 1/2, to regulate neural stem cell self-renewal invivo. Cell Rep. 2013;5:433-44.

82. Baser A, Skabkin M, Kleber S, Dang Y, Gülcüler Balta GS, Kalamakis G, et al. Onset of differentiation is posttranscriptionally controlled in adult neural stem cells. Nature. 2019;566:100-4.

83. Cheng LC, Pastrana E, Tavazoie M, Doetsch F. miR-124 regulates adult neurogenesis in the subventricular zone stem cell niche. Nat Neurosci. 2009;12:399-408.

84. Szulwach KE, Li X, Smrt RD, Li Y, Luo Y, Lin L, et al. Cross talk between microRNA and epigenetic regulation in adult neurogenesis. J Cell Biol. 2010;189:127-41. 
85. De Chevigny A, Coré N, Follert P, Gaudin M, Barbry P, Béclin C, et al. miR-7a regulation of Pax6 controls spatial origin of forebrain dopaminergic neurons. Nat Neurosci. 2012;15:1120-6.

86. Dulken BW, Leeman DS, Boutet SC, Hebestreit K, Brunet A. Single-Cell transcriptomic analysis defines heterogeneity and transcriptional dynamics in the adult neural stem cell lineage. Cell Rep. 2017;18:777-90.

87. Zhang M, Chen D, Xia J, Han W, Cui X, Neuenkirchen N, et al. Post-transcriptional regulation of mouse neurogenesis by Pumilio proteins. Genes Dev. 2017;31:1354-69.

88. Yang M, Yang S-L, Herrlinger S, Liang C, Dzieciatkowska M, Hansen KC, et al. Lin28 promotes the proliferative capacity of neural progenitor cells in brain development. Development. 2015;142:1616-27.

89. Hogan DJ, Riordan DP, Gerber AP, Herschlag D, Brown PO. Diverse RNA-binding proteins interact with functionally related sets of RNAs, suggesting an extensive regulatory system. PLoS Biol. 2008;6:2297-313.

90. Hornbeck PV, Zhang B, Murray B, Kornhauser JM, Latham V, Skrzypek E. PhosphoSitePlus, 2014: Mutations, PTMs and recalibrations. Nucleic Acids Res. 2015;43:D512-D520.

91. Kedde M, Van Kouwenhove M, Zwart W, Oude Vrielink JAF, Elkon R, Agami R. A Pumilio-induced RNA structure switch in p27-3'2 UTR controls miR-221 and miR-222 accessibility. Nat Cell Biol. 2010;12:1014-20.

92. Baser A, Skabkin M, Martin-Villalba A. Neural stem cell activation and the role of protein synthesis. Brain Plast. 2017;3:1-15.

93. Arcila ML, Betizeau M, Cambronne XA, Guzman E, Doerflinger $\mathrm{N}$, Bouhallier F, et al. Novel primate miRNAs coevolved with ancient target genes in germinal zone-specific expression patterns. Neuron. 2014;81:1255-62.

94. Blair JD, Hockemeyer D, Doudna JA, Bateup HS, Floor SN. Widespread translational remodeling during human neuronal differentiation. Cell Rep. 2017;21:2005-16.

95. Zhong S, Zhang S, Fan X, Wu Q, Yan L, Dong J, et al. A singlecell RNA-seq survey of the developmental landscape of the human prefrontal cortex. Nature. 2018;555:524-8.

96. Ravanidis S, Kattan F-G, Doxakis E. Unraveling the pathways to neuronal homeostasis and disease: mechanistic insights into the role of RNA-binding proteins and associated factors. Int J Mol Sci. 2018;19:2280.

97. Pereira B, Billaud M, Almeida R. RNA-binding proteins in cancer: old players and new actors. Trends Cancer. 2017;3:506-28.

98. Yokota Y, Kim WY, Chen Y, Wang X, Stanco A, Komuro Y, et al. The adenomatous polyposis coli protein is an essential regulator of radial glial polarity and construction of the cerebral cortex. Neuron. 2009;61:42-56.

99. Preitner N, Quan J, Nowakowski DW, Hancock ML, Shi J, Tcherkezian J, et al. APC is an RNA-binding protein, and its interactome provides a link to neural development and microtubule assembly. Cell. 2014;158:368-82.

100. Mao H, McMahon JJ, Tsai YH, Wang Z, Silver DL. Haploinsufficiency for core exon junction complex components disrupts embryonic neurogenesis and causes p53-mediated microcephaly. PLoS Genet. 2016;12:e1006282.

101. La Fata G, Gärtner A, Domínguez-Iturza N, Dresselaers T, Dawitz J, Poorthuis RB, et al. FMRP regulates multipolar to bipolar transition affecting neuronal migration and cortical circuitry. Nat Neurosci. 2014;17:1693-700.

102. Kwan KY, Lam MMS, Johnson MB, Dube U, Shim S, Rašin $\mathrm{MR}$, et al. Species-dependent posttranscriptional regulation of NOS1 by FMRP in the developing cerebral cortex. Cell. 2012;149:899-911.
103. Pilaz LJ, McMahon JJ, Miller EE, Lennox AL, Suzuki A, Salmon E, et al. Prolonged mitosis of meural progenitors alters cell fate in the developing brain. Neuron. 2016;89:83-99.

104. Garcia-Dominguez DJ, Morello D, Cisneros E, Kontoyiannis DL, Frade JM. Stabilization of Dll1 mRNA by Elavl1/HuR in neuroepithelial cells undergoing mitosis. Mol Biol Cell. 2011;22:1227-39.

105. Akamatsu W, Fujihara H, Mitsuhashi T, Yano M, Shibata S, Hayakawa Y, et al. The RNA-binding protein $\mathrm{HuD}$ regulates neuronal cell identity and maturation. Proc Natl Acad Sci USA. 2005;102:4625-30.

106. Kanemitsu Y, Fujitani M, Fujita Y, Zhang S, Su YQ, Kawahara $\mathrm{Y}$, et al. The RNA-binding protein MARF1 promotes cortical neurogenesis through its RNase activity domain. Sci Rep. 2017;7:1155.

107. Silver DL, Watkins-Chow DE, Schreck KC, Pierfelice TJ, Larson DM, Burnetti AJ, et al. The exon junction complex component Magoh controls brain size by regulating neural stem cell division. Nat Neurosci. 2010;13:551-8.

108. Sakakibara S-i, Nakamura Y, Yoshida T, Shibata S, Koike M, Takano H, et al. RNA-binding protein Musashi family: Roles for CNS stem cells and a subpopulation of ependymal cells revealed by targeted disruption and antisense ablation. Proc Natl Acad Sci USA. 2002;99:15194-9.

109. Imai T, Tokunaga A, Yoshida T, Hashimoto M, Mikoshiba K, Weinmaster G, et al. The neural RNA-binding protein Musashi1 translationally regulates mammalian numb gene expression by interacting with Its mRNA. Mol Cell Biol. 2001;21:3888-3900.

110. Chavali PL, Stojic L, Meredith LW, Joseph N, Nahorski MS, Sanford TJ, et al. Neurodevelopmental protein Musashi-1 interacts with the Zika genome and promotes viral replication downloaded from. Science. 2017;357:83-8.

111. Yano M, Hayakawa-Yano Y, Mele A, Darnell RB. Nova2 regulates neuronal migration through an RNA switch in disabled-1 signaling. Neuron. 2010;66:848-58.

112. Saito Y, Miranda-Rottmann S, Ruggiu M, Park CY, Fak JJ, Zhong R, et al. NOVA2-mediated RNA regulation is required for axonal pathfinding during development. Elife. 2016;5:e14371.

113. Zhao PP, Yao MJ, Chang SY, Gou LT, Liu MF, Qiu ZL, et al. Novel function of PIWIL1 in neuronal polarization and migration via regulation of microtubule-associated proteins. Mol Brain. 2015;8:39.

114. Zhang W, Kim PJ, Chen Z, Lokman H, Qiu L, Zhang K, et al. MiRNA-128 regulates the proliferation and neurogenesis of neural precursors by targeting PCM1 in the developing cortex. Elife. 2016;5:e11324.

115. Licatalosi DD, Yano M, Fak JJ, Mele A, Grabinski SE, Zhang C, et al. Ptbp2 represses adult-specific splicing to regulate the generation of neuronal precursors in the embryonic brain. Genes Dev. 2012;26:1626-42.

116. Li Q, Zheng S, Han A, Lin CH, Stoilov P, Fu XD, et al. The splicing regulator PTBP2 controls a program of embryonic splicing required for neuronal maturation. Elife. 2014;3:e01201.

117. Zheng S, Gray EE, Chawla G, Porse BT, O’Dell TJ, Black DL. PSD-95 is post-transcriptionally repressed during early neural development by PTBP1 and PTBP2. Nat Neurosci. 2012;15:381-8.

118. Zhang M, Ergin V, Lin L, Stork C, Chen L, Zheng S. Axonogenesis is coordinated by neuron-specific alternative splicing programming and splicing regulator PTBP2. Neuron. 2019;101:690-706.

119. Hayakawa-Yano Y, Suyama S, Nogami M, Yugami M, Koya I, Furukawa T, et al. An RNA-binding protein, Qki5, regulates embryonic neural stem cells through pre-mRNA processing in cell adhesion signaling. Genes Dev. 2017;31:1910-25. 
120. Hayakawa-Yano Y, Yano M. An RNA switch of a large exon of Ninein is regulated by the neural stem cell specific-RNA binding protein, Qki5. Int J Mol Sci. 2019;20:1010.

121. Hamada N, Ito H, Nishijo T, Iwamoto I, Morishita R, Tabata H, et al. Essential role of the nuclear isoform of RBFOX1, a candidate gene for autism spectrum disorders, in the brain development. Sci Rep. 2016;6:30805.

122. Mao H, Pilaz L-J, McMahon JJ, Golzio C, Wu D, Shi L, et al. Rbm8a haploinsufficiency disrupts embryonic cortical development resulting in microcephaly. J Neurosci. 2015;35:7003-18.

123. Zou D, McSweeney C, Sebastian A, Reynolds DJ, Dong F, Zhou $\mathrm{Y}$, et al. A critical role of RBM8a in proliferation and differentiation of embryonic neural progenitors. Neural Dev. 2015;10:18.

124. La Rosa P, Bielli P, Compagnucci C, Cesari E, Volpe E, Vecchioli SF, et al. Sam68 promotes self-renewal and glycolytic metabolism in mouse neural progenitor cells by modulating Aldh1a3 pre-mRNA 3'-end processing. Elife. 2016;5:e20750.

125. Storbeck M, Hupperich K, Gaspar JA, Meganathan K, Carrera LMÍ, Wirth R, et al. Neuronal-specific deficiency of the splicing factor Tra2b causes apoptosis in neurogenic areas of the developing mouse brain. PLoS ONE. 2014;9:89020.

126. Murn J, Zarnack K, Yang YJ, Durak O, Murphy EA, Cheloufi S, et al. Control of a neuronal morphology program by an RNAbinding zinc finger protein, Unkempt. Genes Dev. 2015;29:501-12.

127. Zhao C, Sun G, Li S, Shi Y. A feedback regulatory loop involving microRNA-9 and nuclear receptor TLX in neural stem cell fate determination. Nat Struct Mol Biol. 2009;16:365-71.

128. Shibata M, Nakao H, Kiyonari H, Abe T, Aizawa S. MicroRNA9 regulates neurogenesis in mouse telencephalon by targeting multiple transcription factors. J Neurosci. 2011;31:3407-22.

129. Shibata M, Kurokawa D, Nakao H, Ohmura T, Aizawa $S$. MicroRNA-9 modulates Cajal-Retzius cell differentiation by suppressing Foxg1 expression in mouse medial pallium. J Neurosci. 2008;28:10415-21.

130. Dajas-Bailador F, Bonev B, Garcez P, Stanley P, Guillemot F, Papalopulu N. microRNA-9 regulates axon extension and branching by targeting Map1b in mouse cortical neurons. Nat Neurosci. 2012;15:697-9.

131. Clovis YM, Enard W, Marinaro F, Huttner WB, De Pietri, Tonelli D. Convergent repression of Foxp2 3'UTR by miR-9 and miR-132 in embryonic mouse neocortex: implications for radial migration of neurons. Development. 2012;139:3332-42.

132. Shu P, Wu C, Ruan X, Liu W, Hou L, Fu H, et al. Opposing gradients of microRNA expression temporally pattern layer formation in the developing neocortex. Dev Cell. 2019;49:764-85.

133. Zhao C, Sun G, Ye P, Li S, Shi Y. MicroRNA let-7d regulates the TLX/microRNA-9 cascade to control neural cell fate and neurogenesis. Sci Rep. 2013;3:1329.

134. Bian S, Hong J, Li Q, Schebelle L, Pollock A, Knauss JL, et al. MicroRNA cluster miR-17-92 regulates neural stem cell expansion and transition to intermediate progenitors in the developing mouse neocortex. Cell Rep. 2013;3:1398-406.

135. Fei JF, Haffner C, Huttner WB. 3' UTR-dependent, miR-92mediated restriction of Tis 21 expression maintains asymmetric neural stem cell division to ensure proper neocortex size. Cell Rep. 2014;7:398-411.

136. Chen Y, Bian S, Zhang J, Zhang H, Tang B, Sun T. The silencing effect of microRNA miR-17 on p21 maintains the neural progenitor pool in the developing cerebral cortex: MiR-17 targets p21 in cortical neural progenitors. Front Neurol. 2014;5:132.

137. Pollock A, Bian S, Zhang C, Chen Z, Sun T. Growth of the developing cerebral cortex is controlled by MicroRNA-7 through the p53 pathway. Cell Rep. 2014;7:1184-96.
138. Abdullah AI, Zhang H, Nie Y, Tang W, Sun T. CDK7 and miR210 co-regulate cell-cycle progression of neural progenitors in the developing neocortex. Stem Cell Rep. 2016;7:69-79.

139. Gaughwin P, Ciesla M, Yang H, Lim B, Brundin P. Stagespecific modulation of cortical neuronal development by MmumiR-134. Cereb Cortex. 2011;21:1857-69.

140. Sun G, Ye P, Murai K, Lang MF, Li S, Zhang H, et al. MiR-137 forms a regulatory loop with nuclear receptor TLX and LSD1 in neural stem cells. Nat Commun. 2011;2:529.

141. Fededa JP, Esk C, Mierzwa B, Stanyte R, Yuan S, Zheng H, et al. MicroRNA-34/449 controls mitotic spindle orientation during mammalian cortex development. EMBO J. 2016;35:2386-98.

142. Lv X, Jiang H, Liu Y, Lei X, Jiao J. MicroRNA-15b promotes neurogenesis and inhibits neural progenitor proliferation by directly repressing TET3 during early neocortical development. EMBO Rep. 2014;15:1305-14.

143. Volvert ML, Prévot PP, Close P, Laguesse S, Pirotte S, Hemphill $\mathrm{J}$, et al. MicroRNA targeting of CoREST controls polarization of migrating cortical neurons. Cell Rep. 2014;7:1168-83.

144. Franzoni E, Booker SA, Parthasarathy S, Rehfeld F, Grosser S, Srivatsa $\mathrm{S}$, et al. miR-128 regulates neuronal migration, outgrowth and intrinsic excitability via the intellectual disability gene Phf6. Elife. 2015;4:e04263.

145. Shin J, Shin Y, Oh SM, Yang H, Yu WJ, Lee JP, et al. MiR-29b controls fetal mouse neurogenesis by regulating ICAT-mediated Wnt/ $\beta$-catenin signaling. Cell Death Dis. 2014;5:e1473.

146. Nishino J, Kim I, Chada K, Morrison SJ. Hmga2 promotes neural stem cell self-renewal in young but not old mice by reducing p16Ink4a and p19Arf expression. Cell. 2008;135:227-39.

147. Zhao C, Sun G, Li S, Lang M-F, Yang S, Li W, et al. MicroRNA let- $7 \mathrm{~b}$ regulates neural stem cell proliferation and differentiation by targeting nuclear receptor TLX signaling. Proc Natl Acad Sci USA. 2010;107:1876-81.

148. Kim DY, Hwang I, Muller FL, Paik JH. Functional regulation of FoxO1 in neural stem cell differentiation. Cell Death Differ. 2015;22:2034-45.

149. Han J, Kim HJ, Schafer ST, Paquola A, Clemenson GD, Toda $\mathrm{T}$, et al. Functional implications of miR-19 in the migration of newborn neurons in the adult brain. Neuron. 2016;91:79-89.

150. Brett JO, Renault VM, Rafalski VA, Webb AE, Brunet A. The microRNA cluster miR-106b 25 regulates adult neural stem/ progenitor cell proliferation and neuronal differentiation. Aging. 2011;3:108-24.

151. Wang F, Tidei JJ, Polich ED, Gao Y, Zhao H, Perrone-Bizzozero NI, et al. Positive feedback between RNA-binding protein $\mathrm{HuD}$ and transcription factor SATB1 promotes neurogenesis. Proc Natl Acad Sci USA. 2015;112:E4995-5004.

152. Romer-Seibert JS, Hartman NW, Moss EG. The RNA-binding protein LIN28 controls progenitor and neuronal cell fate during postnatal neurogenesis. FASEB J. 2019;33:3291-303.

153. Jang HJ, Kim JY, Kim SY, Cho KO. Persistent Lin 28 expression impairs neurite outgrowth and cognitive function in the developing mouse neocortex. Mol Neurobiol. 2019;56:3780-95.

154. Quesnel-Vallières $\mathrm{M}$, Irimia $\mathrm{M}$, Cordes $\mathrm{SP}$, Blencowe BJ. Essential roles for the splicing regulator nSR100/SRRM4 during nervous system development. Genes Dev. 2015;29:746-59.

155. Roberts JM, Ennajdaoui H, Edmondson C, Wirth B, Sanford JR, Chen B. Splicing factor TRA2B is required for neural progenitor survival. J Comp Neurol. 2014;522:372-92.

156. Lampasona AA, Czaplinski K. Hnrnpab regulates neural cell motility through transcription of Eps8. RNA. 2019;25:45-59. 